\title{
Lewis F. Richardson's mathematical theory of war
}

\author{
ANATOL RAPOPORT \\ University of Michigan
}

\section{Introduction}

Developed over a period of some thirty years, Lewis $F$. Richardson's approach to a general theory of large-scale conflict, although treating a wide variety of subject matter, has a sufficiently unified theoretical basis to be called a "system." That is to say, the assumptions underlying the theory are sufficiently lucid and explicit and the derivation of the conclusions is sufficiently rigorous to warrant a critique of the entire system through the examination of its underlying base.

This base has three aspects, which will be examined separately. These are (1) a philosophical aspect, dealing with the nature of large-scale events; (2) a psychologicalethical aspect, dealing with motivations and goals; and (3) a technical aspect, dealing with scientific strategy, that is, the choice of data, the interpretation of data, the invention of theoretical models, and methods for testing the models. First, it is important to point out that all three aspects of Richardson's system-its philosophy, its psychological components, and its methods-have been developed elsewhere. The originality of his contribution is simply in the lengths to which he has gone in combining them into an extensive system.

Richardson's philosophical orientation, that is, his view of large-scale human behavior, derives from the outlook of Malthus, Darwin, Marx, Toynbee, Pareto, and the mathematical economists. His psychologicalethical orientation is traceable partly to the thinking of Jesus, Tolstoi, and Gandhi and partly to that of the pragmatists. His technical methods are identical with the workers in mathematical biology and sociology of the "deterministic school," particularly Volterra, Lotka, Kostitzin, and Rashevsky; and to anyone familiar with the views of these authors, Richardson's exposition has an extremely familiar ring, both the prose and the mathematics.

We shall consider the philosophical orientation first. To give it a name, we shall call it "determinism." Before we go any further, however, we must point out all the dangers inherent in attaching a label with powerful connotations to a view to which the connotations may or may not be appropriate. In a way, one has no choice, since every label has connotations and no set of connotations can be hoped to be completely appropriate in a specific situation. We shall content ourselves with spelling out what we mean by "determinism," particularly by determinism of large-scale events.

Whitehead once pointed out that modern physical science owes an intellectual debt to Greek tragedy, from which it borrowed the deterministic orientation. For the essence of Greek tragedy, according to Whitehead, is its emphasis on the inexorable sequence of events which has its own logic and which imposes this logic on the acts and even on 
the motivations of men. The unfolding of the tragedy is identical with the logic of events becoming more and more apparent. The unraveling of the consequences of a scientific theory has, in Whitehead's opinion, the same flavor. He recounts, for example, the feeling of awe which came over a meeting of the Royal Society when the results of the observations on the eclipse of the sun in 1919 were announced to be strictly in accordance with the predictions of the general theory of relativity. He likens the atmosphere to that in a Greek tragedy at the moment when a messenger arrives to announce an event which exactly fits into the unfolding scheme of fatalistic development.

Complete determinism in this sensethat is, exact agreement of predicted with observed results-is largely confined to astronomy. Nevertheless, the orientation of determinism remains at the basis of orientation in physical science, except in situations dealing with nuclear events. Indeed, determinism has been, until recently, practically synonymous with the scientific outlook, not necessarily as a conviction of the universal validity of determinism but certainly as a definition of what is amenable to scientific investigation.

The question, then, is to what extent is the deterministic outlook valid in areas outside the domain of the physical sciences? If one believes in a broad applicability of determinism, one is to that extent a determinist. But the belief itself has two aspects, first, a metaphysical one, where one holds that somehow determinism is in the nature of things, a fundamental component of being and becoming; second, a methodological one, having to do with the choice of phenomena which seem to corroborate the deterministic view. It is to this latter aspect of determinism that we refer when we class
Richardson with the other determinists, Malthus, Darwin, Marx, Toynbee, etc.

The outlook of all these (and many others) can be summarized thus: whether or not determinism resides in small-scale events, it does reside in large-scale events. Now this view can be supported by various rationales. There is a mystical rationale, for example, that of Hegel, according to which the large-scale determinism is ascribed to some supernatural volition. There is a semimystical rationale, such as that of Marx and Toynbee, who do not mention supernatural determinants of events but who do reify abstractions like "class consciousness" or "civilization" and endow these abstractions with organismic tendencies, such as maturation. There is also a rationale for large-scale determinism devoid of mystical tendencies, deriving simply from the consequences of the postulates of probability theory, in particular from the law of large numbers. Thus one does not have to be a mystic to say, "True, I do not know what will be the outcome of a particular coin toss, but I do know that, in the absence of mechanical bias in favor of heads and tails, the outcome of 1,000 tosses is almost certain to be between 440 and 560 heads and of $1,000,000$ tosses between 498 ,000 and 502,000 heads. I do not know whether I shall return from my long weekend trip alive, but I do know that the number of traffic victims will be between 400 and 700."

It is now recognized that the determinacy of large-scale events even in physics can tolerate just so much analysis into component events. When one considers more and more refined detail, one either arrives at situations with so many variables that it is small consolation to hold on to one's metaphysical conviction that there is determinism there just the same-it is of no use to anyone; or else one arrives at situations in principle indeterminate, at least with respect to 
the only methods of observation at our disposal (as in nuclear events). Thus the argument runs both ways: if one grants that physical determinism has limits on the microscopic end of the scale, one has to grant the possibility that the indeterminacy seemingly inherent in situations involving human motivations, volitions, etc., may disappear as the events are taken on a larger and larger scale. The trend is away from old mystical, teleological determinism and toward a statistical one. Such has been the case in biology. The teleological determinism of Lamarckian evolution is replaced by the fundamentally statistical idea of natural selection inherent in the ideas of DarwinWallace and later worked out in considerable detail by Haldane, Fisher, and Wright.

Determinism in history is still dominated by a semimystical, teleological outlook, as represented in the writings of Hegel, Marx, Spengler, and Toynbee. In contrast to this sort of determinism there are at least two other outlooks. One simply denies historical determinism, declaring that it derives entirely from mystical sources and is nourished by reification of metaphors and illegitimate analogies. Such is the view, for example, of Popper (2), who goes to great lengths to make Hegel appear like a pompous, pretentious fool, which, admittedly, is not hard to do. By extension, Marx's "materialistic" determinism is dismissed as a simple derivative of Hegel's mystique. The dismissal hinges largely on an application of a derisive label, "historicism," to all speculations derived from an idea of historical determinism. The other outlook accepts historical determinism in principle but does not ascribe historical trends to any teleological forces. It seeks to put historical determinism on the same basis as the physical determinism of large-scale events, even to the extent of using mathematical models to describe the course of these events which are very much like the mathematical models of physics. The outlook is, however, non-committal in the sense that it makes no pretense of claiming that the models are an adequate description of the events. Rather its advocates propose a piecemeal approach to the problem, much as is done in the successive approximations of mathematical physics. Starting with models which are simplest to handle mathematically and which have only the barest resemblance to some intuitive notions about what may be happening, the "mathematical historians," or rather the mathematical theoreticians of history such as Richardson and Rashevsky (whose methods are practically identical), seek to derive from such models consequences containing statements about relations among observable variables. Presumably these statements can then be compared with relations actually observed, leading to revisions and refinements of the models.

The choice of variables and models and the evaluation of the conclusions hinge on methodological questions, to be discussed later. Since we are, for the present, confining ourselves to the philosophical aspect of these theories, we shall only restate their metaphysical basis. Their proponents proceed on the assumption of determinism of large-scale historical events. This assumption is rooted in statistical laws governing large-scale events rather than in supernatural or quasisupernatural interference in human affairs. Yet some resemblance of this determinism to the earlier type of, say, Marx is striking. From both, one draws the conclusion that the seeming "freedom of will" intuitively experienced by each individual subjectively is either an illusion or, at any rate, plays no part in the over-all picture. This idea was already inherent in the classical free-market economics antedating Marx. The rationale for the free-market economy has been traditionally just this irrelevance of individual 
motivations to large-scale effects. Everyone pursued his own "self-interest." Yet the sumtotal of the efforts was supposed to add up to beneficent equilibrium of supply and demand. Marx's de-emphasis of individual motivations, moral considerations, etc., is of the same character. The northerner in midnineteenth century United States was convinced that slavery was morally wrong. The southerner was equally convinced that it was morally right. Both, according to the Marxist view, were playing out the roles assigned to them by the economic conflict between a predominantly feudal and a predominantly industrial system. Again, freedom appeared to eighteenth-century political thinkers as an unalienable right. By a strange coincidence, freedom of contract and freedom from personal obligation were necessary conditions for an expanding capitalist economy.

There is a curious passage in the closing chapter of Tolstoi's War and Peace which has the same flavor as the more explicit Marxist arguments:

Ever since the law of Copernicus was discovered and proved, the mere recognition that not the sun, but the earth moves has destroyed the whole cosmography of the ancients. By disproving the law, it might have been possible to retain the old conception of the movements of the heavenly bodies; but without disproving it, it would seem to be impossible to continue studying the Ptolemaic worlds. But as a fact even after the discovery of the law of Copernicus, the Ptolemaic worlds long continued to be a subject of study.

Ever since the first person said and proved that the number of births or crimes is subject to mathematical laws, that certain geographical and politico-economical laws determine this or that form of government, that certain relations of the population to the soil lead to migrations of peoples-from that moment the foundations on which history was built were destroyed in their essence.

By disproving those new laws, the old view of history might have been retained. But without disproving them, it would seem impossible to continue studying historical events, merely as the arbitrary product of the free will of individual men. For if a certain type of government is established, or a certain movement of peoples takes place in consequence of certain geographical, ethnographical, or economic conditions, the free will of those persons who are described to us as setting up that type of government or leading that movement cannot be regarded as the cause.

And yet history goes on being studied as of old, side by side with laws of statistics, of geography, of political economy, of comparative philology and geology, that flatly contradict its assumptions. ...

Just as in astronomy the difficulty of admitting the motion of the earth lay in the immediate sensation of the earth's stationariness and of the planets' motion, so in history the difficulty of recognizing the subjection of the personality to the laws of space and time and causation lies in the difficulty of surmounting the direct sensation of the independence of one's personality. But just as in astronomy, the new view said, "It is true, we do not feel the movement of the earth, but if we admit its immobility, we are reduced to absurdity, while admitting its movement, we are led to laws"; so in history, the new view says, "It is true, we do not feel our dependence, but admitting our free will, we are led to absurdity; admitting our dependence on the external world, time, and cause, we are led to laws." In the first case, we had to surmount the sensation of an unreal immobility in space, and to admit a motion we could not perceive of by sense. In the present case, it is essential to surmount a consciousness of an unreal freedom and to recognize a dependence not perceived by our senses.

We turn to the psychological-ethical aspects of Richardson's system. It is legitimate to ask whether ethical convictions are ever relevant in a theory which purports to be scientific. To this we can reply that, whether or not such convictions are relevant in the explicit formulation of the theory, they may very well be relevant in the formation of the concepts leading to the theory. Certainly there is a more intimate connection between what is desired and what is thinkable than can be explicitly admitted in the formulation of a theory. Moreover, it is hard to draw the 
line between metaphysics and ethics, that is, between convictions of what reality is like and convictions as to what one ought to do. Science is unthinkable without a metaphysical conviction that nature is "regular," which in certain circumstances is translatable into a theological conviction that "God is neutral," at least with regard to certain events. A thoroughgoing critique of an economic or social system is possible only after certain emotional commitments to that system have been loosened, and this usually involves an ethical reorientation.

And so, to investigate the consequences of "returning good for evil" in certain conceptually quantifiable situations (as Richardson does) is possible only if it appears at all thinkable to do so, and this, in turn, involves a certain ethical orientation.

It would be going too far to say that Richardson's theories are dominated by the peculiar Christian ethical principles which require the return of good for evil, etc. Indeed, in at least one instance he explicitly disavows this origin. But certainly an awareness of these principles and even, perhaps, a certain sympathy with them are prerequisite in order to examine their consequences applied on the scale of international relations as persistently as Richardson does. To be sure, he also examines other hypotheses, in particular, the intimidating effects of large threats (such as are supposed in the formulation of the present United States policy). By the very framework of his formulation, i.e., the mathematical equations, Richardson is forced to disclaim any a priori position as to the preferable policies. Still, there is no question about where his personal preferences are. It remains true that there are very few examples where a scientist set out to prove one thing (which he had believed in) and came out proving the opposite. There are conspicuous examples of this sort, but they are conspicuous precisely because they are so rare. Some of this harmony between prior emotional commitment and final conclusions is no doubt attributable to unconscious biases operating in the investigation itself. But the choice of problem probably plays an equally important role. One chooses the problems which, one intuitively feels, will tend to corroborate one's convictions, and the intuitions of outstanding investigators are more often right than wrong.

There is one more point to be made about the relevance of ethical conviction to the formulation of a theory of action, which, I think, is important in Richardson's case. On the surface it appears that Richardson is impartially comparing the efficacy of different means of attaining different consequences. For example, his variables contain "threat components" such as armaments; cooperative components of international behavior, such as trade; motivational components, such as grievances, etc. He derives mathematical consequences of the quantitative relations among these components. The center of interest, however, is on three types of consequences: (1) disappearance of threats-unlimited co-operation, (2) stabilization of threats-balance of power, and (3) unlimited growth of hostility-war. Now the very emphasis of these results in each model points to Richardson's center of interest. The important thing for him is the amount of hostility among nations and its rate of change. This in itself reflects a certain ethical orientation.

To see this clearly, suppose, for example, Richardson were interested not in world peace but in the attainment of unlimited power by the British Empire. The central interest of his investigations would then be not the stability or instability of international relations but the parameters of military and economic might. He might, in the interest of "scientific impartiality," abstract from the 
power of a particular state, but this would not prevent him from pursuing his mathematical investigations along the lines of power coalitions, of conflicts and their probable outcomes, of strategies, etc. Instead, he chose to investigate the etiology of conflict as one would investigate the etiology of disease.

Richardson's conclusions are pragmatic. If one wishes to decrease tensions, under such and such circumstances one does so and so. But a pragmatic approach has itself a particular ethical flavor. In some ethical systems there is no room for any pragmatic consideration. Any given situation may call for action of a particular kind, because it is "just" or "honorable" or "the thing to do." For example, the ideal of making every punishment fit the crime is usually devoid of any pragmatic considerations.

Indeed, the pragmatic justifications usually attached to the punitive conception of penology and to international politics may be no more than rationalizations of dogmatic rather than pragmatic motivations. At any rate, a pragmatic rationale for policy requires confirmation, and the willingness to hold formulation of policy in abeyance until reasonable confirmation is obtained constitutes in itself an ethical standpoint, since such a willingness implies a denial of traditional ethical convictions.

Just as certain ethical orientations "show" through Richardson's formulations, so do certain psychological ones. The "transactional" nature of human events is central. That is to say, the "overtones" of human acts are taken into account, probably to a greater extent than appears, at least, in the traditional pronouncements of our decisionmakers. The results of war preparations appear in Richardson's treatment not only as the war materials themselves but also as changes in behavior of the potential opponents (and sometimes of potential friends, who are not always aware against whom the preparations are directed).

However, it is with the translation of these psychological and philosophical convictions into an explicit theory with which Richardson was concerned. Before we turn to the technical aspects of Richardson's work, we must examine in somewhat greater detail the methodological implications of his basic philosophical position, namely, that it is possible to treat human affairs scientifically, that is, by deterministic methods.

As we have said, two types of determinism appear in science: the classical determinism of Newtonian mechanics and the more recently discovered statistical determinism of large numbers. The Newtonian determinism was thought to be absolute. It had a metaphysical basis clearly expressed by Laplace in his famous passage about the possibility of predicting exactly the entire future course of events in the universe by taking a single "reading" of the state of affairs. Naturally, such a feat could be performed only by a superhuman intelligence, but the admission of its theoretical possibility stresses the deterministic orientation of the age.

The development of physics was nourished by this framework of thought. The physicist discovered "laws," presumably manifestations of the determinism of nature. In addition to the laws derived from the basic principles of motion and from the law of gravity (the foundations of celestial mechanics), a great many other laws were discovered as the investigations of the physical world went on: laws dealing with the behavior of elastic bodies, with that of gases, with the transfer and transformation of heat, with the viscosity of fluids, etc.

One of the great achievements of nineteenth-century physics was the discovery that the great majority of these laws (excepting those of mechanics and electromag- 
netism) were really manifestations not of an "absolute" determinism such as still was surmised to operate in mechanics but of a statistical determinism.

As an example, take the law which (to a first approximation) governs the rate of diffusion of one gas through another. It states that the flow across an imaginary boundary will be proportional to the concentration gradient across that boundary. How much determinism is there in this law? No more than in any situation subject to the operations of the laws of chance where numbers are involved comparable to the numbers of molecules comprising the gas. If a molecule of a gas is as likely to go from one side of the boundary to the other as vice versa, the numbers actually passing across will be proportional to the numbers concentrated in equal adjacent volumes. This and only this operation of the laws of chance needs to be assumed in order to derive the law of diffusion. Accordingly, the laws of chance are assumed to be the basis of the law. Other laws, such as those of viscosity, of gas pressure, of chemical reactions, and many others, are similarly derived.

Superimposed on the laws of chance governing the behavior of large collections of entities, there may be extraneous biases. For example, the motions of water molecules in a cloud may be random with respect to the co-ordinate system fixed to the cloud. But the cloud itself may be moving, blown by wind. If the motions of the water molecules are now examined relative to a fixed system of reference, they will still be chaotic, but a directional bias will be observed. Turning the situation around, we may imagine that a bias imposed on a chaotic movement of entities comprising a mass results in a systematic movement of the entire mass. A similar situation may be assumed to underlie mass behavior. Each individual, governed by his own impulses, desires, etc., may be- have in a way seemingly not related to the behavior of others. However, the resultant of the behaviors of millions of individuals may be entirely stable. Moreover, secular trends can be seen as results of extraneous "forces" imposed on the mass. These trends may be unnoticeable if the behavior of only a few individuals is studied (just as the movement of the whole cloud cannot be surmised on the basis of motions of a few molecules). But biases (sometimes very small ones) are nevertheless operating, and the over-all result may be a perfectly regular change in the mass behavior pattern. It is therefore not unreasonable to describe the behavior of the mass by deterministic equations.

Let us now examine the bases of cognition in order better to distinguish between the two methods of attack used by Richardson in his approach to mass behavior. The cognitive process which we call "science" revolves around two methods of obtaining knowledge-deduction and induction. Deduction is usually depicted in elementary textbooks on logic as arguing from the general to the particular, and induction as the other way around. These processes, however, as actually practiced in science, are vastly more complicated than textbook examples. It is a far cry from the syllogism about the mortality of Socrates to the deduction of the Law of Universal Gravitation from Kepler's Laws of Planetary Motion. Yet both are examples of pure deduction. Induction, too, is no more a simple matter of stating a general proposition on the basis of so many observations. Modern techniques of induction, such a statistical inference, are as involved as those of mathematical deduction, largely because they involve not only the making of a generalization but also extricating the degree of confidence with which a given generalization may be made on the basis of given data. 
Intimately intertwined with these logical processes is a metaphysical notion of causality, which appears in a variety of garbs. In classical, deterministic physics, for example, causality, if it is anything at all, is simply logical implication. And since the independent and the dependent variables in the classical equations of physics are usually interchangeable, so are "cause" and "effect." While we still prefer to think that forces cause acceleration rather than vice versa, there is no such asymmetry of causation in the equation. If we look at electromagnetic phenomena (which, being more recently discovered than those of mechanics, do not involve so many deep-seated prejudices) we see this interchangeability much more clearly. For who is to say whether the change in the electrostatic field creates the magnetic field or vice versa?

It fares otherwise with causality in the more empirical areas of science, those which have not yet been reduced to systems of equations. Here the memory of Hume's devastating critique of causality as a compelling notion still lingers. Hume, it will be recalled, emphasized the fundamentally empirical basis of our notion of causality (as distinguished from a rational basis) and so shattered the hope of ever establishing the necessity of causality in nature.

The search for empirically established causal relations must be governed by more modest aims. There are degrees of certainty concerning any surmised causal relation. The weakest criterion is an ordinary statistical correlation. A stronger criterion, in most cases sufficient to establish a causal relation for all practical purposes, is a manipulable correlation. That is, if one observes that by making one of the variables assume some arbitrary value we can induce another variable to assume a statistically correlated value, we have more confidence in the surmised causal relation (the manipulated vari- able being assigned the role of "cause"). The strongest criterion is obtained via the controlled experiment, the ideal method of physical science. Here all the variables thought to be in any way relevant are held constant except the one manipulated and the one presumed to be the "effect." Ideally, to every value of the former there should correspond a unique value of the latter.

This method, or at least the philosophy associated with it, has spilled over from physical into biological science and finally into the behavioral sciences. Voices are raised among those concerned with human behavior against the relevance of controlled experiment in that last area. Perhaps such voices would not command the attention they do if controlled experiment involving the most interesting areas of human behavior were not so difficult to perform. The fact remains that such experiments are extremely difficult. Consequently, the payoff of such strategy has remained erratic, and arguments purporting to show the irrelevancy of the strategy appear reasonable.

The devotee of natural science attributes the slow progress of behavioral science to the sheer complexity of the systems involved. In order to control the variables whose effect is not desired, it is, first of all, necessary to know what those variables are. But they are so many that it is next to impossible to ferret them out, let alone control them.

Whether non-trivial controlled experiments on behaving systems are indeed hopelessly difficult is a matter of opinion. The behavioral scientist often foregoes the controlled experiment either because of the difficulty of imposing controls or because he does not know, at least at the start of his investigation, which variables he should control and which he should study. He then relies on statistical correlations.

Statistical methods are complementary to 
controlled experiments in the sense that they depend for their success on the operation of very many variables. The ideal situation from the statistical point of view is where there are so many variables that they become "confounded," that is, tend to cancel one another's effects. This cancellation provides the "constancy" analogous to the constancy of controlled variables in a controlled experiment. Thus it is hoped that a sufficiently large sample of a population is so representative of the whole population that any two such samples behave in the same way, that is, have the same average values of the variables of interest. Therefore, if it is possible to select a sample for an unusual value of one variable and it is observed that another variable also exhibits an unusual value, there is a possibility that the two are causally correlated. It is only a possibility, but it provides a toe hold, a working hypothesis. Complications of all sorts haunt the statistician's search for causal correlations, largely in the form of intervening non-controllable, and non-observable variables and in the form of spurious correlations. The very notion of "causal correlation" becomes hopelessly vague in this context, for seldom are the variables manipulable.

In the absence of manipulation, it appears, at first, that operational meaning cannot be assigned to "cause," and metaphysical discussions becloud the issues. In one sense, however, a meaning can be assigned to "cause," even in the absence of manipulable variables. In this context, statistical investigations play a major part. It is possible to define cause as that which underlies the departure from the expected. For example, in testing whether a coin is fair, we may throw it several thousands of times. If the fraction of heads does not depart too much from 0.5 , we say the coin is fair; if it does, we say the coin is biased. Put in another way, this means that an inquiry into causes is not undertaken if observations agree with statistical expectations and is undertaken if they do not. There is no answer to the question "Why do heads appear approximately half the time?" Somewhere there is an answer to the question "Why do heads appear more frequently than tails?" This conception of causality as that which underlies a departure from statistical expectation is the basic idea in what is called in statistics the null hypothesis.

Applications of null hypotheses are very numerous. It is desired, for example, to investigate the "reality" of so-called accidentproneness. The null hypothesis is established, that is, the supposition that accidents occur purely "at random." What "purely at random" means is not always easy to say, but certain mathematical criteria of equality and independence of probabilities can be used. The distribution of accidents with relation to people and time intervals in a given situation is then computed on the basis of the null hypothesis. Any significant departure from these computed distributions then points to the existence of biases (in common parlance, "causes") and justifies efforts for their further identification.

These, then, are Richardson's tools of reasoning. They are the standard tools of natural science: deduction, as embodied in deriving the consequences of a mathematical model; induction, as embodied in the search for statistical regularities; the search for causes, as embodied in the null hypothesis and in singling out for attention instances in which data depart from values expected on the basis of the null hypothesis.

Just one more word concerning mathematical models and their use. To begin with, mathematical models are algorithms of reasoning. That is to say, they enable the theoretician to reason where ordinary "common-sense" logic fails. How easily commonsense logic can fail can be seen in a trivial 
example. Suppose a man is engaged by a firm for a salary which is to be a fixed proportion of the net profit of the firm, such net profit to be computed after the deduction of this salary. Common-sense logic may lead one to suppose that the problem of computing the salary is insoluble, because one cannot compute the salary without knowing the net profit and one cannot compute the net profit without knowing the salary. Both statements are true, yet the salary is simple to determine if only the gross profit is known. In fact, if $P$ is the gross profit and $f$ is the fraction of the net profit to be paid as salary and $x$ represents the salary, we have

$$
x=f(P-x) ; x=\frac{f P}{1+f} .
$$

What mathematics can do that commonsense reasoning cannot is to consider in toto the sometimes intricately interwoven causes and effects so as to disentangle the final effects. It goes without saying that the conclusions cannot be expected to be more accurate than the assumed relations between the variables, and this brings us to the other crucial characteristic of mathematical models.

Contrary to a prevalent meaning of "model" in many theoretical formulations, the main function of a mathematical model is not an "explanatory" one. A mathematical model is more characteristically a point of departure rather than a point of arrival in the construction of a theory. In this way it is akin to the null hypothesis, which, incidentally, also often involves the construction of a mathematical model. In most cases, null hypotheses are made so that they can be refuted. As a by-product of the refutation of the null hypothesis, biases are usually discovered which point to the direction of search for "causes." It is much the same with mathematical models. These models are often deliberately made simple-minded, with full knowledge that they do not represent reality. Their chief value is that they lead to compelling consequences. These consequences are then compared with observations. As often as not, the derived consequences do not agree with the observations. But then the direction and magnitude of the departures may indicate the direction of further search. Richardson fully realizes both the usefulness and the limitations of mathematical models and repeatedly emphasizes both.

In what follows we shall examine one instance of the inductive approach and two instances of mathematical model construction employed by Richardson in his mathematical theory of human deadly conflict.

\section{Statistics of Deadly Quarrels (7)}

The first task in the study of any phenomenon is to describe it. But what is one to describe? Countries are described by their topographical features, by flora, fauna, behavior of inhabitants; animals and plants are described by their structural parts; a historical period by its important events. In each case selection is inevitable. Selection is determined by what the describer has learned from the descriptions of others of similar things and partly by his own preoccupation.

Historians have traditionally described wars in terms of selected events that have preceded the wars (in the overwhelming majority of cases, these have been taken to be "political"); in terms of the strategy of the campaigns; and in terms of selected events that have followed the wars (again overwhelmingly political).

Next in frequency to these political-military descriptions of wars we encounter economic descriptions. That is, the selected events described as preceding a war (which are thus offered by implication to be the 
“causes") predominantly involve trade, technology, resources, etc. Also the war itself is frequently described in economic terms (for example, the American Civil War in terms of the relative economic potentials of the combatants), and so are the consequences.

Richardson chooses to fix his attention on a variable not often considered: the number of war dead. Having focused on that variable, he erases for the time being the distinctions between international and civil wars, between wars and insurrections, and even between wars, on the one hand, and riots and murders, on the other. He classes all these phenomena under a single generic term, "deadly quarrels," that is, encounters between human beings in which, as a result of deliberate action, deaths result. To my knowledge, Richardson does not use the criterion of deliberate aggressive action; but this criterion is implied, because fatal automobile accidents, for example, are not included in "deadly quarrels." Except for this implied criterion, which links the events with something called the "aggressive instinct" (although on that basis some might wish to include automobile accidents), the etiology of deadly quarrels is neglected in this purely descriptive phase of Richardson's investigations.

The deadly quarrels are thus classified according to the single criterion of magnitude. This magnitude Richardson defines as the logarithm to the base 10 of the number of deaths resulting. Included are the deaths resulting from the fighting directly and also those from starvation or disease immediately attributable to the fighting. We have, then, magnitudes ranging from zero for simple murders $\left(\log _{10} 1=0\right.$ ) to $7 \pm \not / 2$ for the two world wars, in which the dead are reckoned in tens of millions. Most murders involve the death of one victim, but two or three victims are also common. For example, two victims result if the murderer commits suicide or is eventually executed. Note the deliberate ignoring by Richardson of the difference between murder and "retribution," which ordinarily is carefully distinguished. A murder and the execution of the murderer are lumped together and appear in Richardson's data as simply a deadly quarrel of magnitude $0.3\left(\log _{10} 2 \cong 0.3\right)$. This classification dramatically emphasizes Richardson's approach to the study of deadly quarrels initially divorced from all moral or etiological considerations.

A crucial task in such a study is to find reliable sources of data. Data for murders are available from the criminal statistics of "civilized" states. Data for large-scale wars

\section{TABLE 1}

\section{Number of Fatal QuarReLs Recorded}

\begin{tabular}{ccccc} 
Date of & \multicolumn{3}{c}{ Ends of Ravan of Magaitude } \\
S rudy & $7 \pm t$ & $6 \pm$ & $6 \pm 1$ & $4 \pm 1$ \\
$1941 \ldots \ldots \ldots$ & 1 & 3 & 16 & 62 \\
$1947 \ldots \ldots \ldots$ & 1 & 3 & 90 & 60
\end{tabular}

are not so accurate but are also on hand. The inaccuracy of data on war dead is somewhat mitigated by the logarithmic scale of magnitude. Thus a tenfold error in war dead is reflected in an error of only one magnitude. Statistics on smaller wars, insurrections, riots, etc., become progressively less reliable and in many cases totally unavailable. Pichardson's starting point was Quincy Wright's Study of War. From there, he continued through the consultation of some seventy history books. The period chosen for study was 1820-1929, in some cases extended to 1945 . The results for the largest four magnitudes obtained in two separate studies are shown in Table 1.

The consistency of the two studies is encouraging and gives Richardson some confidence in the data. However, his collection of data on deadly quarrels of the next smaller magnitude $(3 \pm k)$ has continued to 
grow to the time of writing, and so the number can be recorded as "at least 188." Extending the period to 1945 and including murders (taken from the statistics of seventeen countries) the data up to date are given in Table 2.

Data on deadly quarrels of magnitudes $y_{2}-2 \frac{1}{2}$ (3-300 dead) are missing from this study. But a curve extrapolated from the wars to murders seems to indicate that some character of such distributions, in order to take them as a basis of comparison with the distributions of deadly quarrels classified by magnitudes. The rationale for such distributions is the following. ${ }^{1}$ Suppose we have a collection of objects divided into classes according to the frequency of their occurrence. The classical example is some large verbal output (say a book or a collection of newspapers). A given word belongs in class $f$ if

TABLE 2

$\begin{array}{lccccc}\text { Ends of range of magnitude ..... } & 7 \pm \frac{1}{2} & 6 \pm \frac{1}{2} & 5 \pm \frac{1}{2} & 4 \pm \frac{1}{2} & 3 \pm \frac{1}{2} \ldots . \text { Murders } \\ \text { Observed no. of fatal quarrels... } & 2 & 5 & 24 & 63 & \geqq 188 \ldots 6 \times 10^{6}\end{array}$

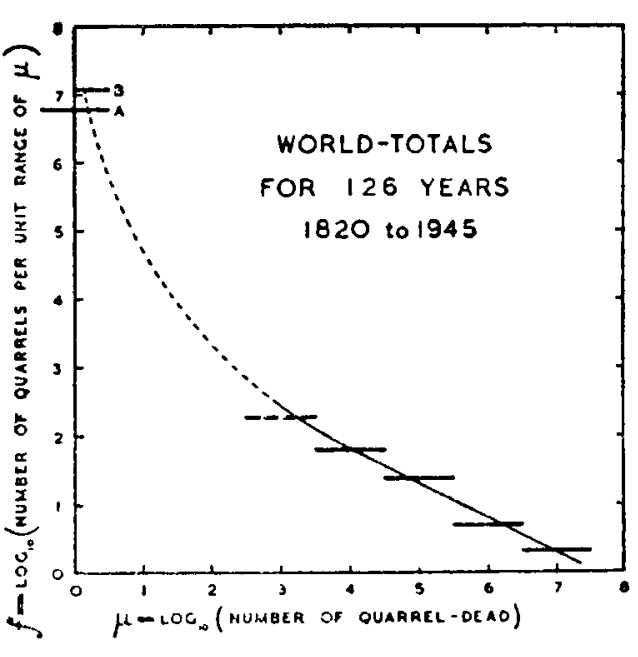

Frc. 1

sort of statistical relationship is discernible between the magnitudes of the quarrels and the frequency of occurrence (see Fig. 1).

If the units of the ordinate are changed to $\log _{10}$ (number of quarrels per unit range of dead) instead of per unit range of magnitude, the curve shown in Figure 2 results. We note that this curve is an ordinary size versus frequency curve plotted on log-log paper. A straight-line graph would indicate an exact power formula (number of quarrels inversely proportional to some power of the number of dead).

At first, we shall note only the general it has occurred $f$ times in the sample. Now let the sample grow (as the book is written or as the newspapers continue to be printed). When a word which is currently in class $f$ appears again, it passes into class $f+1$. Consequently, the class $f$ loses a member and class $f+1$ gains a member. But if a word of class $f-1$ appears, then the class $f$ gains a member. The appearance of a new word adds a member to class 1 . The mathematical problem consists in calculating the equilibrium distribution, in which further additions will come at just the right rate so as not to disturb the relative magnitudes of the various classes. This equilibrium distribution will depend, of course, on the statistical rule by which additions are made. In the distributions in question it is assumed that the probability of the occurrence of a word of a certain class is proportional to the total number of occurrences in that class up to that point, and also that there is a certain constant probability of a new word occurring. Under this assumption, equilibrium conditions are obtained of the sort described.

It is now profitable to compare the distri-

1 The theoretical discussion to follow is taken not from Richardson's writings but from some recent studies (cf. H. A. Simon, "On a Class of Skew Distribution Functions," Biometrika, XLII [1955], 425). 
bution of the deadly quarrels by magnitudes with the statistical distribution just described. The comparison would make sense only if a similar rationale were found for the distribution of deadly quarrels. By a stretch of the imagination, such a rationale can indeed be found. It is not to be taken seriously. It is to serve only as a starting point in the search for a plausible rationale for the way deadly quarrels are distributed.

Suppose we tabulate the deadly-quarrel deaths occurring throughout the period examined by Richardson ( 125 years) by classes according to their relevance to previous deaths. Thus a murder, which we suppose to have no relevance to a previous death of this sort, would constitute the start of a new class, while a death occurring in some war would be classed with the other deaths of the same war. This classification is analogous to the classification of the word sample. Each deadly quarrel corresponds to a word; each of its deaths to the number of occurrences of that word; the number of deadly quarrels of a given magnitude to the number of different words with a given occurrence frequency.

If we now suppose that the chance that each successive death falls into a given category (that is, belongs to a deadly quarrel of a given class) is proportional to the total number of deaths which have already occurred in that class and also that there is a constant probability that each successive death will be unrelated to the previous ones (i.e., a murder), we have essentially the same accumulation process as the one which is supposed to govern the accumulation of word occurrences in a large sample.

There is one discrepancy, however. Characteristic of the tabulation of deaths in a deadly quarrel is the fact that the termination of the quarrel is defined by some external criteria. For example, the end of the Franco-Prussian War is taken at a certain date. Thereafter, the occurrence of war deaths is attributed to some other war. In other words, whereas a word is considered identical with all its occurrences regardless of when it occurred, the deaths are tabu-

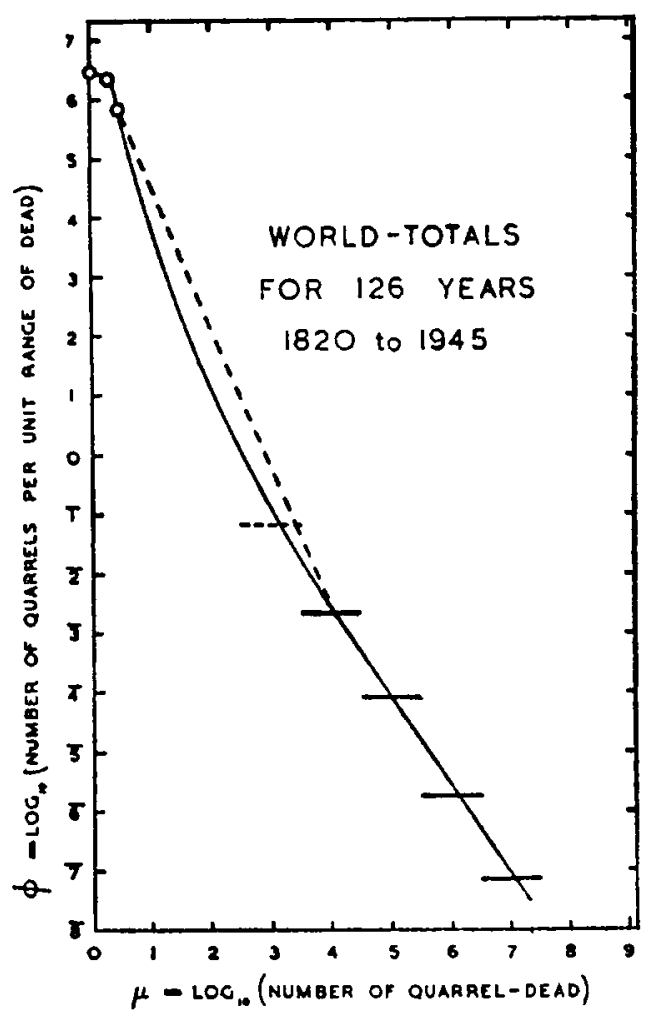

Fic. 2.-The horizontal scale extends from a single person on the left to the population of the world on the right. The three dots at the left-hand top represent the murders. The short horizontal lines represent the wars grouped by magnitudes. One of these lines is dotted, because it should be raised to an unknown height.

lated by when and where they occurred. Time and place, not the nature of the deaths, define a deadly quarrel. At this time, we are not in a position to evaluate the seriousness of this discrepancy, and so we shall simply pass it over. We want to see to what extent a stochastic process previously described for distributions of words in lan- 
guage samples and for a great variety of other distributions (sizes of cities, numbers of species in genera, etc.) can account for the distributions of the deadly quarrels.

With this reservation in mind, let us examine Richardson's distribution of deadly quarrels by magnitude (Fig. 2). We note that in the region of large-scale wars (average magnitudes 4-7), the slope of the line is -1.50 (estimated by maximum-likelihood method), while in the region of interpolation, filled to connect the wars with the murders, the slope is -2.38 . The latter value is consistent with the stochastic model we have proposed, but the former is not. This is because the stochastic model leads to a distribution wherein the inverse power
We see, therefore, that the stochastic model which has been successfully applied to a great many phenomena to explain the relation between magnitude and frequency fails when applied to the statistics of deadly quarrels, at least in the upper range. Far from being discouraging, this failure should be encouraging to future theoreticians who may want to study this field. The exclusion of large-scale deadly quarrels from the class of processes explainable by rather simple operations of the laws of chance (as other various phenomena are reasonably explained) may lead to the discovery of some specific or anomalous properties of this particular phenomenon (the genesis of deadly quarrels).

TABLE 3

STATISTICS OF BANDITRY

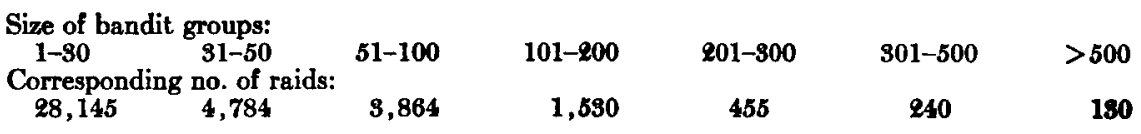

(corresponding to the negative slope of the line on log-log paper) is greater than 2. The excess over 2 depends on the birth rate of the new entities. Powers smaller than 2 cannot be accounted for by this process. Simon (op. cit.) has shown, however, how powers smaller than 2 can be accounted for. If, after the total sample has reached a certain size, there are no more "births," it turns out that the power is no longer constant but increases with the magnitude of the quarrel. In this case the "average" power can assume any value greater than 1 . Thus it may be smaller than 2. But, for this model to fit, the inverse power would have to become larger for quarrels of larger magnitude, whereas the graph shows the opposite. Moreover, whereas in the word sample it is easy to imagine the cessation of "births" (the author has used up his vocabulary), the cessation of "new" violence seems a most unrealistic assumption in historical perspective.
There remains, of course, the possibility that the small negative power $(-1.50)$ of the distribution at the large end can be explained by taking into account the tabulation we have mentioned, in which wars are considered to have been terminated at specific dates. But this remains to be shown theoretically. The question of the reason for this anomaly remains open.

Let us now turn to another part of the distribution, the range of the "middle" quarrels, where the slope is supposedly -2.38 . Since the magnitude of the inverse power is here greater than 2 , it is conceivable that the general stochastic process described above is applicable in this range. As we have said, this is the slope of a line which serves as an interpolation between wars and murders. The actual data on deadly quarrels in this range are missing. But another set of data provides an interesting clue of what these values may be. 
In 1935 an extensive survey was made by the Japanese on the bandit groups operating in Manchuria (then Manchukuo). The statistics compiled are given in Table 3. Treating these data in the same way as the data on deadly quarrels, we have a graph similar to that of Figure 3 . The variables related here are, of course, different. But if one makes the not unreasonable assumption that

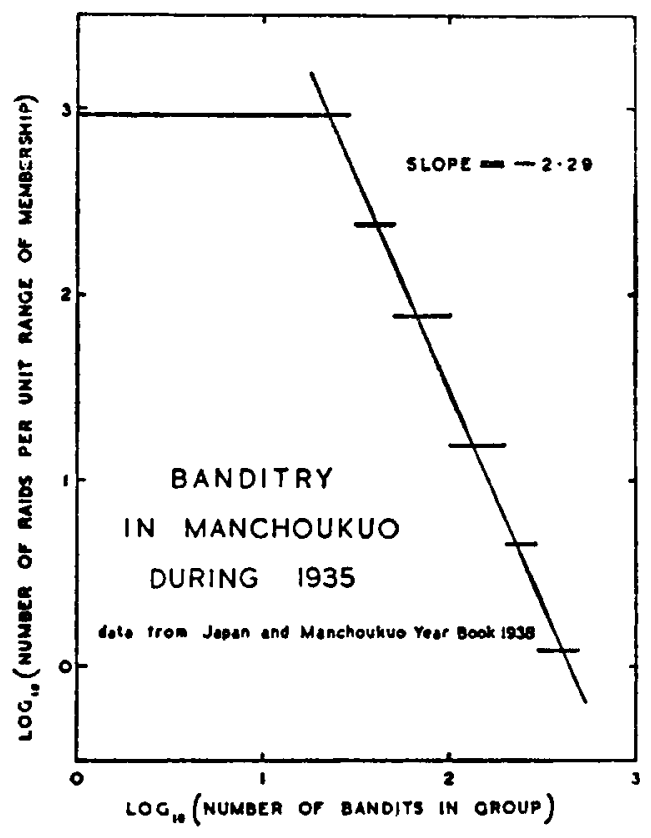

FIg. 3

the number of dead in any bandit raid is, on the average, proportional to the size of the bandit group, the graph of the logarithm of the number of dead against the logarithm of the number of incidents, both per unit range, will have exactly the same shape as the corresponding graph of number of raids versus size of bandit groups. (Since the variables are logarithms, the constant of proportionality introduces only an additive constant into the linear relation.)

The slope of the line in Figure 3 is -2.29. The interpolated slope for the medium range of deadly quarrels was -2.38 . The question of whether this is a coincidence or whether the Manchurian banditry data actually fill the gap and so make the linear dependence of the logarithm of incidence against the magnitudes of the deadly quarrels cornplete is, to say the least, an intriguing question.

To pursue this question, Richardson considers another quite unrelated set of data, namely, the Chicago gangs during the period of their greatest florescence, the 1920's. He exhibits Table 4. Treating these data in the same way as those on the Man-

TABLE 4

\begin{tabular}{|c|c|c|}
\hline $\begin{array}{l}\text { No. of Members } \\
\text { in Gangs } \\
\text { (Inclusively) }\end{array}$ & $\begin{array}{l}\text { No. of } \\
\text { Such Gangs }\end{array}$ & $\begin{array}{l}\text { Gangs per } \\
\text { Unit Range of } \\
\text { Membership }\end{array}$ \\
\hline 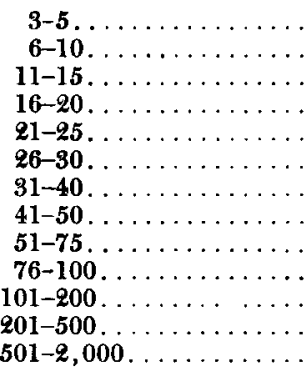 & $\begin{array}{r}37 \\
198 \\
191 \\
149 \\
79 \\
46 \\
55 \\
51 \\
26 \\
25 \\
25 \\
11 \\
2\end{array}$ & $\begin{array}{l}12.3 \\
39.6 \\
38.2 \\
29.8 \\
15.8 \\
9.2 \\
5.5 \\
5.1 \\
1.04 \\
1.00 \\
0.25 \\
0.37 \\
0.0013\end{array}$ \\
\hline
\end{tabular}

churian bandits, he gets, for the slope of the line analogous to those of Figures 2 and 3 , the value -2.30 , again in close correspondence with the desired magnitude and almost identical with that for Manchurian bandits. Even the flattening of the curve at the low-magnitude-high-incidence range is duplicated by both the Manchurian and the Chicago data. How are these findings to be interpreted?

Richardson's work is not widely known and, to my knowledge, has not been critically discussed. There has been, however, recently a discussion of another similar compilation of data, primarily by G. Zipf. This discussion was summarized elsewhere (3). The broad outlines of this evaluation will be 
given here because they are pertinent to a critical discussion of Richardson's work.

Two opposite positions have been taken on the interpretation of the statistical regularities noted by Zipf and others who have compiled similar sets of data. One extreme position was taken by Zipf himself. $\mathrm{He}$ postulated an extremely general principle operating in all human behavior, which he called the "Principle of Least Effort" and purported to show that the statistical regularities governing the distribution of word occurrences in language samples, the sizes of cities, the distribution of incomes, of sizes of firms, etc., are all deducible from the operation of that principle.

It can be surmised from Zipf's own remarks that the idea of the Principle of Least Effort was inspired by the Principle of Least Action in physics, which is a very general formulation of the laws of both mechanics and electrodynamics from which the behavior of all mechanical and electrodynamic systems may be deduced. But whereas the deductions of methematical physics are deductions in the strictest sense of the word, that is, they are chains of reasoning leading to compelling conclusions, Zipf's arguments are nothing of the kind. Indeed, Zipf's attempt to demonstrate the operation of a general principle in large-scale human behavior must be considered a failure. However, this bringing together of masses of statistical data and the raising of the question about possible general principles underlying them remain positive achievements.

To Zipf, the determinism of large-scale human behavior (mass behavior) seemed to be of the "absolute" sort, akin to the determinism of celestial mechanics or even more -a teleological determinism, a trend toward predestined ends. At the other extreme is a view espoused by $H$. Simon, denying the operation of "cosmic" principles in human behavior. According to this view, the regu- larities observed result from the operation of the laws of chance. The regularities are only steady states which are limiting states of certain stochastic processes.

The well-known statistical distributions, such as the normal distribution, are easily deducible from a very large class of stochastic processes. No one in our day would care to insist that the normal distributions of sizes of peas and of human beings and of the deviation from the bull's-eye in target practice are consequences of teleological forces of nature. Zipf's distributions are typically limiting cases of the distributions described above. They are called "logarithmic normal," that is, they are distributions of a random variable whose logarithm is normally distributed. The "etiology" of such distributions is as easy to account for as that of the normal distribution. Whereas a normal distribution of the values of a random variable results if the variable suffers increments independently of its value, the logarithmic normal distribution results if the increments are suffered proportionately to the absolute value of the variable. Thus it is not surprising that sizes of cities are approximately logarithmic normally distributed if we make the assumption that both increments and decrements of population will be proportional to the populations and if we wait long enough for the steady state to be established.

There is an intermediate view between that of Zipf and that of Simon. B. Mandelbrot, in attempting to explain the observed word-frequency distributions, postulated an "optimization principle," according to which the amount of information transmitted by each word in a large sample of verbal output is maximized while the average "cost" per word is kept constant. What this "cost" (presumably the cost of transmission or of decoding) may be is immaterial to the theory and hence gives credence to its generality. To be sure, Mandelbrot did not go any- 
where near so far as Zipf did. He has confined his attention to a particular aspect of human behavior-communication, governing which he postulated a reasonable, longrange optimizing principle. The main virtue of Mandelbrot's approach, however, is not so much the reasonableness of his modest hypothesis as the genuineness of the deductions. His arguments are indeed mathematical, and thus the conclusions must stand or fall with the premises. No accusation of non sequitur can be brought against such a theory.

The question now arises whether the argument about the presence or absence of an optimization principle (or, equivalently, of a maximization or minimization principle) is not really only a verbal argument wherever statistical regularities are concerned. If the reader will be patient with a digression, I will make my meaning clear.

Only two genuine kinds of "force" (as force is defined in mechanics) are known: gravitational and electrostatic. ${ }^{2}$ Intuitively, "force" is felt to be something which "creates motion." This intuitive feeling does not quite coincide with the definition of physical forces. The latter are defined as something responsible for changes in motion. However, there is a situation where the intuitive notion and the rigorous definition coincide. If a body is constrained, then a force acting upon it would be "that which causes motion" if the constraint were removed.

Now the determinism of mechanics and electrodynamics can be thought of as the certainty that a force acting on a constrained body is always such that, if the constraint were removed, the body would move in the direction of smaller potential energy (would

2 Other, seemingly unrelated, forces are assumed to be operating within atomic nuclei. A clear understanding of these forces is still lacking. start trading its potential energy for kinetic).

There are other such situations where the direction of change upon removal of constraints can be definitely predicted. If the constraining walls of a vessel suddenly break, any gas contained therein will expand; if a partition is removed between two gases, the gases will diffuse through each other. But the forces associated with this type of predicted direction of change are not the "pure" forces, as the gravitational and electrostatic forces are. The determinism observed is rather the determinism of large numbers. The regularity of observed changes is statistical regularity.

It is quite permissible, however, to talk about diffusion pressure, osmotic pressure, etc., as if they were forces and to enter them so into equations. The physicist is used to working with equations containing forces, and he is glad when natural phenomena can be described in such terms.

Let us now pass to biology. The biologist often speaks of "pressures" operating on populations-for example, the pressure of mutation or the pressure of selection. The demographer, too, sometimes talks of pressures of increasing populations. It is convenient to employ such terms, and, if such pressures can be expressed as "forcelike" variables entering equations of mathematical models, much can sometimes be gained in the construction of a theory. It is clear, however, that the directional trends resulting from such pressures are only statistical trends and not deterministic ones, such as those resulting from the operation of "pure" forces. The equations of mechanical equilibrium and those of a statistical steady state may look similar on paper, but the physical reality underlying each is quite different.

Let us now return to the argument concerning the nature of the "reality" underlying various statistical distributions. Zipf and other teleologists talked as if this "reality" is 
akin to the operation of "real" forces. Statisticians prefer to insist that the underlying "reality" consists of stochastic processes. To the extent that both can describe phenomena successfully, both these assumed "realities" can, of course, map on the same set of equations, and, to the extent that both sets describe the events with equal accuracy, there is no deciding between the two kinds of theory on that level of verification.

Is this, then, all there is to it? Is the argument only an argument about the way to use language? In a way, yes; but different uses of language have different consequences. The statistician, in keeping his attention on the stochastic process, avoids falling into mysticism. Thus the statistical interpretation of evolution and adaptation "debunks" the teleological props which in pre-Darwinian days (and to some extent today with many philosophers and even biologists) were considered necessary to explain the predominantly unidirectional history of life. Lamarckianism is now held by most biologists to be a delusion. On the other hand, the theoretician who persists in talking about directional trends and in giving them names may get hold of important theoretical constructs indispensable for a good theory. The classical example is the notion of entropy in thermodynamics. Even after it has been shown that the trend toward greater entropy in isolated systems is only a statistical trend, the result of an underlying stochastic process, the usefulness of the entropy concept has not diminished. It remains a central notion in thermodynamics and in physical chemistry.

The entropy concept is not derivable from classical deterministic physics (mechanics and electrodynamics). Its only connecting link with unified physical theory is via the theory of probability. Similarly, the seeker for trends in different types of behaving systems must reckon with a loss of firm foot- ing in a unified theory. He may discover "laws" of behaving systems which are not linkable to a unified view of nature through any known deterministic laws. Both the romantically inclined and the strictly empirically oriented investigator will not be disturbed by this disconnectedness. Each will gladly accept laws of living organisms and of larger organized aggregates as peculiar to specific levels of organization. Goethe, for example, who was not quite, but almost, a scientist and certainly a philosopher of science, was rather elated by the striking differences between living and non-living matter. $^{3}$

One who would pursue theoretical unity must take another view. He eschews the recognition of laws governing special behaving systems unless these laws can be shown as consequences of some unifying principle. The theory of probability has been the most promising such principle so far. It has already linked the laws of thermodynamics to those of mechanics. It has explained away the apparent teleological foundations of evolution. Hence the statistician's skepticism of postulated "cosmic principles": so much can be done with the laws of chance that the inventors of "cosmic principles" don't know about.

There need be no quarrel between the statistician and the organismically oriented investigator of large-scale systems if (1) the latter recognizes that his "principles" are only names given to certain statistical trends and (2) the former recognizes the heuristic value of giving names to statistical trends, thus promoting them to theoretical constructs. There is, of course, always a possi-

`Cf. Mephistopheles' complaint:

"And ever circulates the newer, fresher blood. It makes me furious, such things beholding. From Water, Earth, and Air unfolding A thousand germs break forth and grow." 
bility that entirely new "real" forces or principles may be discovered, such as the vitalists hope for. So far, the search has not been successful. One of the difficulties is the lack of criteria for recognizing such new principles when and if they are found.

If the purely heuristic value of organismic principles is granted and their "as-ifness" recognized, the organismic investigator and the statistician can work hand in hand. Provisional citizenship can be granted to new concepts as they are postulated. The statistician's job remains in "explaining these concepts away."

We return to Richardson's interpretation of the relations between size and frequency of occurrence of deadly quarrels, on the one hand, and between the size and the frequency of bandit raids and gangs, on the other. He chooses for his unifying principle "aggregation for aggression," under which he naturally subsumes both the Manchurian bandit raids and the organization of the Chicago gangs. He postulates a "general law" governing the formation of such aggregations and their activity and cites as evidence the almost exactly equal slopes of the regression lines discussed above. If such a general law is granted, it is only a step to a general law governing deadly quarrels, if one assumes the number of victims proportional to the sizes of the aggressive groups. Further evidence in this direction is provided by the closeness of the slopes extrapolated from wars to murders to the slopes governing aggressive groupings.

How good is the evidence of a general law governing the formation and activity of aggressive groups? We have seen that the middle range of the frequency versus magnitude graph can be accounted for by a stochastic process of the sort suspected to be operating in very many extremely varied situations where certain probabilities govern the successive increments or decrements suffered by classes. The coincidence of the parameters governing the distribution of Manchurian raids and Chicago gangs is impressive, as is the circumstance that this value fits into the interpolation between wars and murders. Still, the specificity of this parameter for "organization for aggression," as Richardson puts it, can at this stage have no more than the status of a hypothesis. The analysis of a supposed underlying stochastic process reveals that, at least in the distribution of gang sizes, the parameter is directly connected to the birth rate of the gangs.

However, a valuable by-product of Richardson's investigation emerges. If the slope in question is indeed symptomatic of "organization for aggression," slopes characteristic of other types of organization should be different. Why not compile similar data on many organizations ranging from juvenile gangs to bird watchers' clubs and see whether classification by the values of the slope makes any sense as related to classification by some sociological criterion?

Finally, the examination of the supposed stochastic process shows that the slope is not a free parameter. As we have said, it is related to some "birth rate" and can be calculated from it. If data on such birth rates are obtained, the distributions lose all degrees of freedom. If they still fit the data, the argument that they are nothing more than products of laws of chance is practically conclusive. If not, "teleological" hypotheses of the sort Richardson makes still merit some attention.

Let us now look at the extreme smallmagnitude end of the scale, involving deadly quarrels of one, two, and three victims. Here data again become available in murder statistics. As we have already pointed out, Richardson estimates the relative frequencies of the one-, two-, and three-victim cases on the basis of extremely meager evidence. 
But we are not concerned here with the validity of the data. We are only commenting on the possible methods applicable to the evaluation of such data on theoretical grounds when and if such data become available.

We must now point out that the inversepower formula of the frequency versus magnitude distribution derived from the stochastic process is only an approximation. It holds good for large magnitudes but not for small ones. There is, however, another formula (involving the so-called "beta function") which is exact and applies to the entire distribution. This function allows the calculation of the theoretical relative frequencies of the one-, two-, and three-victim quarrels, once the inverse power of the approximate formula is known. For the value of the inverse power -2.3 (which is the supposed slope of the line for the middle magnitudes), the ratio of single-victim to double-victim quarrels should be somewhat smaller than $3 \frac{1}{2}$, while the ratio of doublevictim to triple-victim quarrels should be somewhat larger than 2. From Richardson's data, these ratios turn out to be about $5: 4: 1$, that is, with a strong bias in favor of the two-victim affair. The paucity of the data warrants no conclusion, but the bias is in the direction one would expect if a compulsion of one-to-one retribution were operating. At any rate, the method illustrates the usefulness of the null hypothesis. One calculates the theoretical expectations on the basis of some reasonable stochastic process, notes the departure from the expectation, and thus obtains a toe hold for speculation about the possible underlying causes.

Richardson in his statistical study of deadly quarrels was content to gather the data and to describe them quantitatively in an entirely empirical manner. He did, however, raise the question of whether the consistency of the slope for the interpolated middle- magnitude quarrels with the distribution of gangs was indicative of some characteristic of "organization for aggression." Having examined his data in the light of a stochastic model proposed elsewhere for a variety of frequency versus magnitude distributions, we see that the stochastic model cannot account for the whole picture. The stochastic model fits best for the interpolated range, which coincides with the size distribution of gangs. Whether or not similar reasoning can be extended to fit the larger wars and the very small deadly quarrels is an open question. Possibly real discontinuities exist, which must be accounted for by other than statistical considerations. At any rate, the chief merit of this work (apart from bringing to light a wealth of data, which may be used in future work in other theoretical approaches) seems to be in its potentialities for raising interesting theoretical questions.

\section{Etiology of Deadly Quarrels}

The temptation to look for lineal causeeffect relations, especially where events vita] to our survival are involved, always persists. Such has been the case in medicine. Such is the case in the field yet unnamed (irenics?) which is concerned with the etiology of conflict and with the methods of resolving them. The more mature view, to which all serious investigators are driven sooner or later, is that there is no single cause of any complex phenomenon. In giving a class of events a name (like "war" or "cancer") we tend to think of the whole class as an entity, whose "origin" is some other such category. Where controlled experiments are possible, at least some manipulable causes may be discovered. Where there is no opportunity for controlled experiment, one is reduced to a search for correlations. Established correlations are a much weaker result than established manipulable causes. But the converse of this proposition also holds, namely, the 
absence of correlations disqualifies pretty definitely the causal status of either of the uncorrelated events. (Exceptions may exist when the effect of some variable is thoroughly camouflaged by the effects of others or where the zero correlation results from a phase lag.)

In this spirit Richardson proceeds to examine the claims made for various "pacifiers" of deadly quarrels (8). A "pacifier" is a condition whose presence makes the outbreak of a deadly quarrel less likely or its termination more likely. Hence the discovery of pacifiers would be a step toward the clarification of the etiology of conflicts, just as the discovery of an alleviating agent for a disease (for example, vitamins) is sometimes helpful for understanding the etiology of the disease. We might say in passing that, although the discovery of cures may seem of greater significance than the discovery of the sources of disease, the latter type of knowledge carries the greatest payoff in the long run. However, in the case of war, as in the case of any scourge which has become unbearable, more effort is directed toward the search for cures than toward the search for causes.

Here is a list of pacifiers, offered at various times and compiled by Richardson:

1. Distraction by sports.-When baseball chases war threats off the front pages, some may scoff at the frivolity of public interest, but it may be a sign of healthy absence of war-mindedness. If symptom and cause are interchangeable (as some behaviorists sometimes maintain), deliberate distraction of this sort may be of use. Richardson doubts that such distractions could be maintained permanently.

2. Hating a different group of people.While conceding that this method may be pragmatically sound in deflecting hatreds, Richardson points out that it is hardly con- ducive toward pacifying the world as a whole.

3. Directing hatred inward.-This sort of displacement was suggested in 1947 by C. G. Jung. Richardson professes respect for this view but does not pursue its implications. It can also be argued, however, that such a program, if achievable, would be highly dangerous. Some psychologists and psychiatrists (for example, E. Fromm and B. Chisholm) have held that self-hatred resulting from guilt feelings is a most common source of aggression.

4. Armed strength.-This is the "official" view in the United States, to the extent that an official view can be said to exist in a nontotalitarian state. That it has a de facto, if not a de jure, existence may be noted from the fact that it may not be opposed or even questioned in any context which is likely to result in a broad dissemination of the message. That is to say, while it is perfectly permissible to question the efficacy of armed strength in preventing wars in journals like Conflict Resolution, in sermons, etc., it is not possible to challenge this view in mass media except, perhaps, in the context of a formal debate, where the minority is clearly labeled and explicit. It is not possible to present the opposing view in mass media implicitly, for example, via a short story in a mass-circulation magazine, in a film, in a television serial, or the like. The subject of national defense is held by the censors of the mass media to be as sacred a subject as the FBI or monogamy.

To the efficacy of armed strength as a pacifier, Richardson applies the mildest test, that of testing for simple correlation. Quite aside from the question of whether armed strength is a predominant factor in the prevention of wars, it is instructive to see whether its influence is at all discernible. Richardson plots the armed dead percentage of the population (presumably some 
measure of the suffering undergone by a nation resulting from war) against its preparedness, measured in the prewar "defense" expenditures in pounds sterling per head per year. Absolutely no correlation, positive or negative, is discernible in his plot. It can be argued, of course, that Richardson's indexes are not the right ones, but the fact remains that no better ones have been examined in his time.

Richardson has a great deal more to say on this subject of armed strength as a deterrent to war and, in the same connection, on the role of international trade. His treatment will be discussed in the next section.

5. Collective security.-According to this view, it is possible in any conflict between nations to identify an "aggressor," whereupon a coalition of nations automatically forms to overwhelm the aggressor with superior strength. Armed strength must, of course, also play a part in this sort of prophylactic. But, whereas the simple armed strength of alliances is interpreted as a threat by the state against which the alliances are formed, in the collective security system, until the aggressor is identified, there is no specific enemy.

Richardson dismisses collective security on the basis of no precedent. Statistics of wars show that predominantly they were (1820-1929) of the one versus one type. Admittedly, this is a weak argument. If "no precedent" is to be taken seriously, then the search for effective prophylactics or pacifiers against deadly quarrels is futile. In view of the flexibility of the term "aggression" (thanks to the flexibility of the term "self-defense"), collective security does not seem a hopeful solution; but so far the argument for or against it cannot be adequately defended by any objective data.

6. Fewer frontiers.-In one of his studies, Richardson calculates the correlations between the number of frontiers which a state has and the number of external wars it has waged. The correlation is 0.77. Another promising lead. "But of course," Richardson remarks, perhaps wryly, "frontiers are not easily altered."

7. Intermarriage.-Richardson claims that frequency of intermarriage qualifies as a pacifying influence on the populations which intermarry and cites examples, without, however, any quantitative or statistical support. The identification of "cause" and "effect" in the relation between intermarriage and alleged deficiency of conflict is, of course, difficult in the absence of opportunities for controlled experiment. Richardson, however, argues stoutly for intermarriage as an effective pacifier.

8. Common language and common religion.-Here the results are not consistent. Richardson concludes that in China there is evidence that common language (or religion) might have acted as a pacifier. The common possession of the Spanish language, on the other hand, seems to have had the opposite effect. The results are not, of course, to be taken seriously. In China vast areas were organized for long periods under common governments. Latin America, where Spanish is predominantly spoken, is a crazy quilt of small sovereign states. Nevertheless, these same political facts may reveal something about the role of language and religion in promoting rivalry and organized conflict within the groups which are the bearers of the languages and religions in question. If the Spanish language and militant Catholicism were antipacifying influences, they may have been partially responsible for the political disunity of Spanish America (as contrasted with Anglo-America) and thus indirectly for the prevalence of strife.

Besides intermarriage, whose effects Richardson does not treat mathematically, Richardson views international trade and loyalty to common government as the most 
pacifying influences. The theory which treats of international trade will be discussed in the next section dealing with arms races. We conclude the present section with an account of Richardson's statistical approach to the role of common yovernment.

The question posed by Richardson is the following: Is allegiance to a common government a pacifier? If so, how can such pacifying effect be deduced statistically? One could begin by counting all deadly quarrels among opponents who owe or have owed allegiance to a common government (for example, civil wars) and compare the number with the number of international conflicts. But such a comparison would have no statistical significance unless the expected numbers (on the basis of the null hypothesis that the pacifier does not exist) could be estimated. Accordingly, Richardson undertakes the construction of a mathematical model based on such a null hypothesis.

Noting that some wars have been partly civil and partly international, he prefers to count not wars but pairs of opponents, civil, foreign contiguous (with common boundary) and foreign non-contiguous. The result is Table 5. There is thus a regular gradation. As the magnitude of deadly quarrels decreases, the ratio of the pairs of civil opponents to total pairs increases. Murders are, of course, practically all instances of "civil deadly quarrels" because of the proximity of the opponents. By extension of the argument, it can be concluded that the deadly quarrels of smaller magnitude would be more predominantly of the civil type. Turning the argument around, one can assume that geographical contiguity provides opportunity for strife. This assumption is corroborated by the high correlation between the number of external wars waged by a state and the number of its frontiers (0.77), mentioned above. Therefore, for a construction of a null hypothesis concerning the effect of common government as a pacifier, it is necessary to find some measure of opportunity for conflict provided by geographical contiguity.

The idea is to count the instances of fighting among those who could have fought. The magnitudes of the quarrels and the populations involved must also somehow enter the calculations. This is an extremely difficult matter. The assumptions which Richardson finally offers are admittedly crude and rather farfetched. Only one thing can be said in their favor, which must under

TABLE 5

Deadly QUaRRels, OF TyPe "ONE Versus ONE," THAT ENDED ANYWHERE IN THE

WORLD FROM 1820 TO 1945 INCLUSIVE

\begin{tabular}{|c|c|c|c|c|}
\hline \multicolumn{5}{|c|}{ 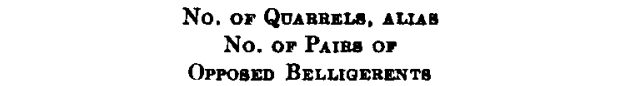 } \\
\hline $\begin{array}{c}\text { ENDs or } \\
\text { Ruvax or } \\
\text { MaGa'* } \\
\text { TODE }\end{array}$ & Civil & $\begin{array}{c}\text { Foreign } \\
\text { Con- } \\
\text { tiguous }\end{array}$ & $\begin{array}{c}\text { Foreign } \\
\text { Non- } \\
\text { con- } \\
\text { tiguous }\end{array}$ & $\begin{array}{l}\text { Ratio of } \\
\text { CiviL to } \\
\text { Total }\end{array}$ \\
\hline 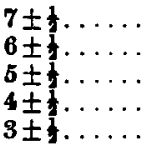 & $\begin{array}{r}0 \\
3 \\
6 \\
10 \\
65\end{array}$ & $\begin{array}{r}0 \\
0 \\
3 \\
15 \\
64\end{array}$ & $\begin{array}{r}0 \\
0 \\
0 \\
2 \\
10\end{array}$ & $\begin{array}{l}3.0 \\
0.7 \\
0.87 \\
0.47\end{array}$ \\
\hline$\pm \frac{i}{2} \ldots \ldots$ & $\dot{.}$ & $\dot{.}$ & . & 1.0 \\
\hline
\end{tabular}

the circumstances be decisive: they are the only assumptions that anyone has ever offered as a starting point of an effort to evaluate objectively (that is, statistically) the possible pacifying effects of allegiance to a common government.

The first task is to compute some norm governing the extent of fighting in a war. One measure is the number of war dead reckoned as a percentage of the population involved. Data on nations defeated show that, overwhelmingly, the war dead fall between 0.5 and 4 per cent of their populations. Since the number of war dead of the winning side is of comparable magnitude and so are the populations, a crude estimate of the range of war dead is between 1 and 
10 per cent of the defeated side. This result can be summarized in the following equation (4):

$$
\begin{array}{ll}
\mu=\log _{10} h-\jmath, & \text { where } \\
& 1.0<j<3.0 .
\end{array}
$$

Here $\mu$ is the magnitude of the conflict, and $h$ is the population of the defeated side. The smaller the $j$, the more severe the war in terms of war dead (since $j$ is subtracted from the logarithm of the population). Data

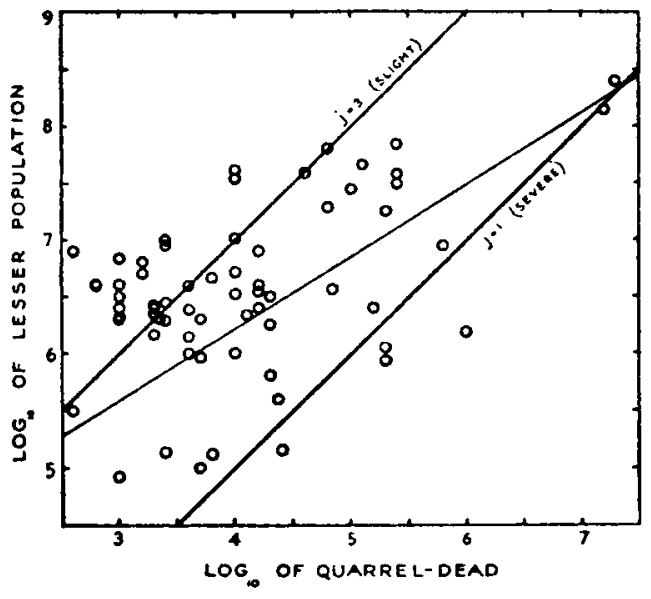

Fig. 4.-Casualties and defeat

collected by Richardson are shown in Figure 4. Each circle is a war. If equation (II) were entirely valid, all the circles would fall between the two $j$-lines. The regression line representing equation (II) would be any line parallel to these and falling between them. Departures indicate the operation of biases. We note, first, that the departures are predominantly in the direction of milder wars (in terms of the percentage of dead) at the smaller-magnitude scale. If, taking this bias into account, we draw a regression line with a slope of less than $45^{\circ}$, we may suspect the operation of a local pacifying influence. That is, the greater the geographical proximity among the opponents (pre- dominantly the case in civil wars), the milder the war.

The bulk of the theoretical investigation on the existence of local pacifiers takes two different directions. One has to do with the frequency and magnitude of conflicts between powers in various degrees of contiguity (for example, insular naval powers, coastal powers, landlocked powers, etc.). The other direction is an attempt to compare the extent of civil and international fighting on the basis of the "fighting opportunities" as presently described. It is this model which can justifiably draw the accusation of extreme naïvete, but, as we have already pointed out, it is the only one of its kind offered, at least to our knowledge.

Choose a historical interval and a range of magnitude of wars. Let the entire population of the globe be partitioned into subpopulations (cells) of four classes: (a) those that had prior governments in common and fought one another; $(b)$ those that had prior separate governments and fought one another; $(c)$ those that had prior governments in common and did not fight one another; $(d)$ those that had prior separate governments and did not fight one another. The idea is to count the number of cells in each class and to compare these numbers with other numbers derived on the basis of some null hypothesis.

The question is how to determine the subpopulations. Here is where Richardson makes the most simple-minded assumption imaginable. He divides the populated areas into hexagonal cells like a honeycomb and modifies the cells so as to satisfy the following criteria: (i) each cell is to contain the same number of persons, $h$; (ii) at most, three cells are to meet at a point; (iii) no cell is to surround another completely; (iv) national frontiers are to lie in the edges of cells; and (v) each cell is to be "homoplatous," i.e., roughly as broad as it is long. 
The purpose of some of these restrictions is not clear. At any rate, the "cellulation" was carried out and showed the following results concerning the ratio of the number of cell edges within nations to the number of cell edges between nations. The idea is that these cell edges are the a priori conceivable opportunities for fighting (as if imaginary boundaries were drawn more or less at random) within states, separating populations of equal magnitude. As is to be expected, the finer the mesh, the greater will be the ratio of intra-national edges to the international edges. Now let $s$ be the number of cells; $C$ the number of cell edges within nations; $F$ the number of cell edges value is still unknown. The test of the null hypothesis will be via the $\chi^{2}$ method, and ${ }_{\downarrow}$ will enter the expression for 2 and therefore must be calculated. We shall presently see how Richardson gets around this difficulty. $\mathrm{He}$ is now ready to compare history with geography, that is, the actual fraction

\section{TABLE 6}

GEOGRAPHICAL FACIS: SUMMARY OF WORLD Total of Celis aNd Edges at MidDLE OF 1910

$\begin{array}{lccc}h=10^{7} & 10^{6} & 10^{5} & 10^{4} \\ s=150 & 1,652 & 16,745 & 168,000 \\ C=159 & 9,373 & 44,200 & 483,800 \\ F=121 & 831 & 3,319 & 12,680 \\ B=1.31 & 4,06 & 13.32 & 38.14\end{array}$

\section{TABLE 7}

COMPaRISON OF HISTORY WITH GEOGRAPHY, YeARS 1820-1945, INCLUSIVE

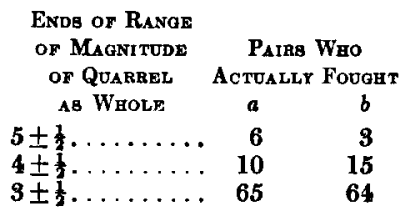

between nations; $B$ the number of cell edges to the sea, polar ice, or desert. The actual numbers are shown in Table 6.

We now have an estimate of $(a+b) /$ $(c+d)$, that is, the ratio of population groups who have governments in common to those who have not: it is $C / F$. We can therefore write

$$
a+c=\tau C, \quad b+d=\tau F,
$$

where $\tau$ is a parameter to be determined. A rather tortuous argument, which we shall not reproduce here leads Richardson to an estimate of , namely,

$$
\tau=\theta\left(T_{2}-T_{1}\right)\left(\mu_{2}-\mu_{1}\right),
$$

where the T's are the limits of the time interval chosen and the $\mu$ 's are the limits of the range of magnitudes of the wars chosen, while $\theta$ is a coefficient whose numerical of civil to foreign wars fought in relation to the opportunities provided by contiguity. These opportunities are calculated for various values of severity, measured by the parameter $i$, which was defined above (Table 7).

A glance at the table indicates that, for magnitude around $5, a / b$ lies between the extremes of $C / F$, so that one might conclude that the actual fighting was distributed between civil and foreign in about the ratio of their respective geographical opportunities. On the contrary, the smaller wars show a different picture: the actual $a / b$ is considerably less than that expected on the basis of opportunities provided. The tentative conclusion is, to quote Richardson, that "for magnitudes less than 4.5 there must have been some influence which repressed civil fighting relatively to foreign fighting." 
It remains to validate this conclusion by a test of significance. Assuming that the apparent contingency has arisen by chance alone, the assumption is tested in the usual manner by calculating

$$
\chi^{2}=\frac{(a d-b c)(a+b+c+d)}{(a+b)(c+d)(a+c)(b+d)}
$$

and by comparing with its distribution for one degree of freedom. Substituting equation (III) in equation (V), we obtain $\chi^{2}$ in terms of $a, b, C, F$, and $\tau$. All these parameters are known with the exception of $\tau$. Here Richardson is again forced into a roundabout argument involving data on wars between contiguous landlocked powers. On the basis of that argument (to the details of which the interested reader is referred to the original source[s]) Richardson concludes that $a$ may be neglected in comparison with $C$, and $b$ in comparison with $F$. When this is done, $\tau$ may be canceled in the numerator and the denominator of equation (V), and $x^{2}$ is expressed in terms of known parameters alone, namely,

$$
\chi^{2}=\frac{b^{2} C}{(a+b) F}\left[\frac{a F}{b C}-1\right]^{2} .
$$

Richardson then computes the value of $\chi^{2}$, taking the data for $j=1, j=2$, and $j=3$. He notes that, for magnitudes around 4 and for $j=3$, the conclusion is not significant. The value of $j$ is, however, uncertain, and 2 is a much more likely value than either 1 or 3 . If the data for $j=2$ are taken, $\chi^{2}$ in the magnitude range $4 \pm y_{2}$ turns out to be 22 , and $P\left(x^{2}\right)$ is zero to six places. On that basis, for magnitudes around 4 an attempted explanation by chance is utterly incredible.

What Richardson has shown is that if any contiguous pair of geographical regions is to be considered as a pair of potential opponents, then the probability that they will have fought in a war of average severity is immensely larger if the boundary that sepa- rates them is an international boundary. At first sight, Richardson's method may seem to be a grotesque circumlocution, culminating in the proof of an utterly self-evident result. On the other hand, it must not be forgotten that civil wars are about as common as international ones. We tend to think more in terms of international wars, because they are treated more extensively in history books and because during the last generation or two the acute social problems posed by war have been thought of in terms of international conflicts. The result obtained by Richardson is due not to the scarcity of civil wars but to a comparison of the occurrence of such wars with the "opportunities" for their occurrence.

The weakest link in this argument is the definition of "opportunity." While Richardson's definition in terms of geographical contiguity is plausible in the context of international conflict, it can hardly be held to be plausible in the context of civil war. Only occasionally are civil wars fought on a regional basis, as the American Civil War. Most civil wars involve clashes of interests not determined by geographical boundaries, for instance, class interests, religious affliations, and political loyalties. True, in the actual fighting, geographical regions will be captured by opposing groups, but these regions can hardly be expected, even roughly, to divide the actual opponents. On this basis Richardson's method of subdividing the world into a meshwork of potential opponents has little meaning. However, the basic methodological idea, namely, comparing the incidence and extent of conflict with the opportunities for conflict with a view of discovering biases either positive or negative which make for departures of what is observed from what is expected on the basis of a null hypothesis, is a sound one. For its meaningful implementation, we must have a more meaningful classification of the 
world population into potentially hostile groups. Such a classification is presumably the job of sociology. The necessity of interdisciplinary co-operation in such projects is thus clearly indicated. So long as single workers must take it upon themselves to do the whole job, defects of the kind that mar much of Richardson's work will be unavoidable.

\section{The Mathematics of Arms Races (6)}

Let us now follow Richardson's method in building a model to represent the relation between two nations, each determined to defend itself against a possible attack by the other. Each nation considers the possibility of attack quite real and, reasonably enough, bases its apprehensions on the readiness of the other to wage war. If the other did not remain in the state of readiness, there would not be any cause of apprehension. All this has a familiar ring, especially when put into the language of a political speech. Richardson introduces the defense minister of Jedesland, who speaks thus in A.D. 1937:

The intentions of our country are entirely pacific. We have given ample evidence of this by the treaties which we have recently concluded with our neighbors. Yet, when we consider the state of unrest in the world at large and the menaces by which we are surrounded, we should be failing in our duty as a Government if we did not take adequate steps to increase the defenses of our beloved land.

The problem now is to translate the minister's remarks into mathematics. He said something about the dependence of the necessity of increasing the defenses on the "unrest of the world," which is all too often a diplomatic euphemism meaning the state of war readiness of Andersland, the neighbor of Jedesland. The first rule in the construction of a mathematical model is to be simple-minded. There will be time enough to become more sophisticated when the inadequacy of the simple-minded assumptions has been demonstrated. The question is how simple-minded can one get? Richardson thinks it is sufficiently simple-minded to take the minister's recommendations literally: the more "unrest" (read the greater the preparedness of Andersland), the greater should be the rate of increase of preparedness in Jedesland, and proportionality is the simplest such relation. Accordingly, what the defense minister has said is

$$
\frac{d x}{d t}=k y,
$$

where $x$ is the state of readiness (the war potential) of Jedesland and $y$ the corresponding quantity in Andersland. The constant $k$ is the "defense coefficient." It tells how an increase in a unit of war potential of Andersland should step up the rate of increase of this potential in Jedesland.

The next simple-minded assumption to make is that the defense minister of Andersland feels exactly the same way about Jedesland. Accordingly, we write

$$
\frac{d y}{d t}=k x \text {. }
$$

What would happen if these feelings were translated into actual accumulation of armaments? Here we have a system which can be completely (that is, dynamically) solved: $x$ and $y$ are given as functions of time:

$$
\begin{aligned}
& x=A e^{k t}+B e^{-k t}, \\
& y=A e^{k t}-B e^{-k t} .
\end{aligned}
$$

Here $A$ and $B$ depend on the levels of the war potentials which the two countries start with. If these happen to have been equal, that is, initially (at $t=0) x=y$, then $B=0$, and both potentials increase at the same exponential rate indefinitely. 
Admittedly, this is only a model. Nothing in the real world increases indefinitely. Yet it is possible to interpret such an "explosion" as a state of affairs leading to war. Certainly, there is some historical evidence which correlates runaway armament races and wars. But let us proceed to make the model somewhat more realistic. We have taken only a single step, with which, according to a Chinese proverb, every journey of 10,000 li must begin.

So let us introduce a restraining effect on the accumulation of armaments. Suppose, again pursuing the policy of simple-mindedness, that a restraint on the rate of accumulation has an effect proportional to the war potential already attained. The equations become

$$
\begin{aligned}
& \frac{d x}{d t}=k y-a x, \\
& \frac{d y}{d t}=l x-\beta y,
\end{aligned}
$$

which can be interpreted in various ways. The coefficients $k$ and $l$, as before, signify an incentive to accumulation of armaments because of the strength of the opponent. The coefficients and $\beta$, on the other hand, have the opposite effect, either fatigue and cost consciousness or else a reassuring effect of one's own strength.

But do armaments depend only on armaments, as the equations seem to imply? Let us hear a real (instead of a composite) statesman on the subject. Richardson quotes Mr. L. S. Amery, M.P., who, commenting on Sir Edward Grey's opinions concerning the role of armaments in armament races, said on July 20, 1936, in the House of Commons:

With all respect to the memory of an eminent statesman, I believe that statement to be entirely mistaken. The armaments were only the symptoms of the conflict of ambitions and ideals, of those nationalist forces, which created the war.
The war was brought about because Serbia, Italy, Rumania, passionately desired the incorporation in their states of territories which at that time belonged to the Austrian Empire and which the Austrian Government were not prepared to abandon without a struggle. France was prepared if the opportunity ever came to make an effort to recover Alsace-Lorraine. It was in those facts, in those insoluble conflicts of ambitions and not in the armaments themselves that the cause of the war lay.

Here we have, then, a debate. What "causes" wars? Sir Edward Grey thought armaments caused wars, and so did Thucydides over 2,000 years earlier, as he wrote: "The real unavowed cause [of the Peloponnesian War] I believe to have been the growth of Athenian power, which terrified the Lacaedemonians and forced them into war."

Mr. Amery thinks otherwise. He believes grievances and passions cause wars, of which armaments are only symptoms. The lineal subject-predicate structure of our languages does our thinking for us. "What causes wars?" we ask. The sentence has the same grammatical structure as "What is this?" The answer to the latter question is expected to be unequivocal. "This is a pear" or "This is a necktie." Obviously a "this" (an answer to a "what") cannot be both a pear and a necktie. Somewhere in the back of our minds is a similar attitude toward the identification of "causes." The answer to "What causes wars?" (or cancer or divorce or juvenile delinquency) is likewise expected to be a one-word answer. We usually disavow such expectations, but they lurk behind every polemic concerning causes.

The mathematician's grammar is of a different sort. His systems usually represent relations between every pair of variables in his set. He starts out by putting down a fairly complete set of relations for a given set of variables and can work his way either down to simpler systems by eliminating 
some dependencies or up to more complicated ones by adding relations or variables. Accordingly, the mathematician can satisfy both Sir Edward Grey's sentiments and Mr. Amery's by writing

$$
\begin{aligned}
& \frac{d x}{d t}=k y-a x+g, \\
& \frac{d y}{d t}=l x-\beta y+h .
\end{aligned}
$$

Now we have three different effects on the rate of accumulation of armaments-the positive effect of the strength of the other, the negative effect of one's own strength, and the effects of "grievances" $g$ and $h$ presumably operating independently, as Mr. Amery would have it. To satisfy Mr. Amery's conception, one would set $k, a, l$, and $\beta=$ 0; to satisfy Sir Edward Grey's, one would set $g$ and $h=0$. But it is instructive to consider the behavior of the whole system without committing one's self to any particular values of the parameters.

Let us do so. We note, first, that there are two straight lines in $(x, y)$ space, along which both $d x / d t$ and $d y / d t$ are zero. The meaning of these lines is the following. For any given value of $y$ (the state of armament of Andersland) there is a value of $x$ (the state of armaments of Jedesland), which Jedesland considers consistent with her security, its sense of what she can afford, and her degree of animosity toward Andersland for other reasons. The set of these points is determined by the equation of the straight line $k y-\alpha x+g=0$. Similarly, for any given value of $y$, there is a state of armaments which Andersland considers satisfactory. If the two lines have a common point, it is conceivable that a balance of power has been achieved: both sides feel right about their security, what they are paying for it and what they are doing about their national honor. There is such a common point, provided that the straight lines intersect, which they will do if they are not parallel. If the two lines are coincident (this happens if the coeffcient in the two equations are all proportional), every point is such a point. We shall disregard the two exceptional cases of parallel and coincident lines.

And so, if the two lines intersect, the point of intersection is a point of equilibrium. The point of intersection can be easily obtained in terms of the parameters $k$, a, $g, l, \beta$, and $h$ by solving the equations of the two lines simultaneously. There is, however, another important consideration be-

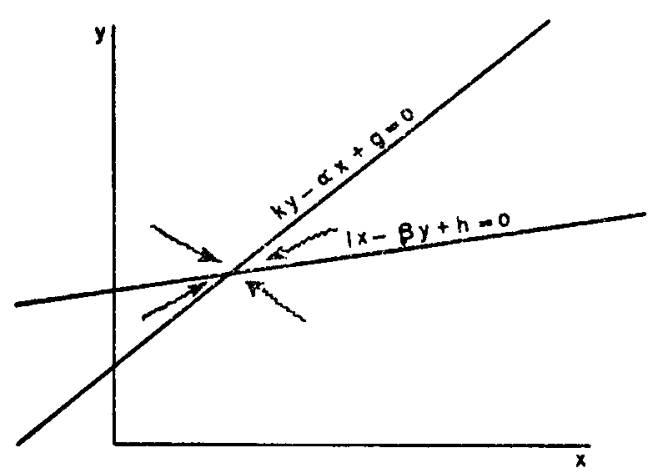

Fig. 5.-The stable armament race, tending toward a "balance of power."

sides the position of that equilibrium, namely, its stability. This depends on the relative slopes of the two lines. Consider Figure 5. Here the slope of Jedesland's line is greater than that of Andersland's.

Now suppose at some time the armaments of Jedesland and Andersland have the values $x$ and $y$, respectively. Jedesland, controlling its own armaments, can move the point $(x$, $y$ ) in the horizonal direction, while Andersland, through its control of the variable $y$, can pull it in the vertical direction. Each will try to pull it toward her own line of equilibrium. The resultant of these pulls will be toward the point of intersection of the two lines wherever the initial point happens to be. Such an equilibrium is called "stable." 
The point $(x, y)$ representing the armaments of the two countries will tend to move toward it. If it is reached and because of some accidental disturbance the point ( $x$, y) moves away from such an equilibrium, it will tend to return to it.

Matters are very different if the slope of Andersland's line is greater, as shown in Figure 6. Here, as can be easily verified, the attempts of both countries to bring the point $(x, y)$ on to their respective line of equilibrium will result in the movement of the point $(x, y)$ away from the intersection.

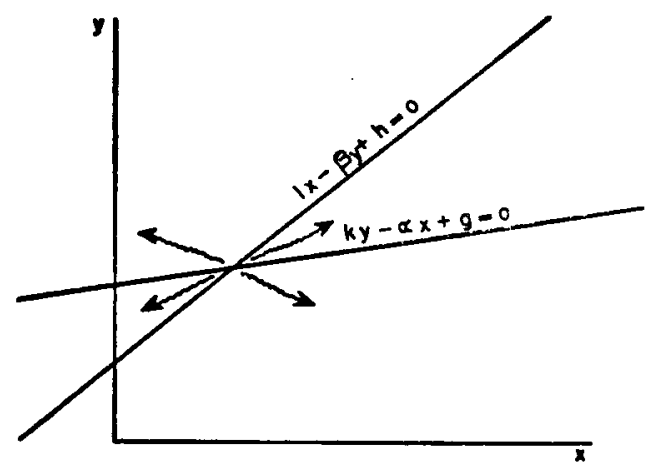

Fic. 6.-The unstable armament race, tending toward either disarmament or war.

Indeed, in this case, the point will either go off to infinity or approach one of the zero axes, depending on whether the initial armaments were above or below the critical values of the equilibrium. Such an equilibrium is called "unstable." In this case, there is a certain "ignition point" such that, if for some reason armaments have increased beyond it, a runaway race will begin.

Translated into a relation among the parameters, the condition of stability is seen to be

$$
\frac{a}{k}>\bar{\beta} \quad \text { or } \quad a \beta>k l, \quad(\mathrm{XIV})
$$

that is, the product of the restraint coeffi- cient is to be greater than the product of the mutual stimulation coefficients.

Now the complete "dynamic" solution of the mathematical model represented by equations (XII) and (XIII) would yield $x$ and $y$ as functions of time and of the parameters $k, \alpha, g, l, \beta, h$, and of the initial values of these variables at some starting point in time. In order to test the model, that is, one would have to compare the actual behavior of $x$ and $y$ with the predicted. If "comparison" is taken literally, this would mean that we should have to know the actual values of all the parameters. We are seldom able to obtain such knowledge directly. What usually happens in subjecting a mathematical model to a test is that at least some of the parameters must be guessed.

A simple example will illustrate our meaning. There is a physical law that says that when a spring is stretched, the elongation is proportional to the force applied (this is the principle of the spring scale).

Expressed as an equation, this law states that

$$
x=x_{0}+k F,
$$

where $x$ is the variable length of the spring; $x_{0}$ is the "natural" length; $F$ is the impressed force; and $k$ is some constant. Now $x_{0}$ can be directly measured. But $k$ cannot be $d i$ rectly measured; it is computed by dividing some arbitrary elongation $x-x_{0}$ by the corresponding force. The law, as stated, says nothing about the magnitude of $k$. All it says is that $k$ is constant. This constant is a "free parameter," that is, it can be anything (as long as its value is the same for all elongations) without the validity of the theory being challenged.

The more free parameters there are in a theory, the "weaker" the theory, because the more degrees of freedom we have, to make the predictions of the theory fit the observations. Given a sufficient number of 
free parameters, any continuous curve drawn through a set of data can be expressed by a suitably chosen formula. Therefore, the "strength" of a theory is measured not so much by the goodness of fit between its predictions and observations as by the paucity of the free parameters involved.

The mathematical model we have described contains six free parameters, and, as long as they remain free, it is an extremely weak theory, that is to say, it is easy to fit many sets of data with it, but the goodness of fit is not really a severe test and thus not too significant theoretically. Therefore, to make the theory meaningful, efforts should be directed toward establishing the "reality" of the parameters in terms of the content of the theory, to show that they are not merely constants selected to fit the data but measurable quantities or, at least, useful theoretical constructs.

Before the parameters can be estimated, it is necessary to interpret the main variables, $x$ and $y$, which, as we have seen, represent in some sense the hostility of the two nations toward each other. The question arises whether they may not be signed quantities, that is, whether their negative values may not represent the opposite of hostility. Richardson takes the volume of trade between two countries as an index of their co-operation, while the armament expenditures are an index of their hostility. Again the oversimplification may be almost painful to contemplate, and again it must be emphasized that the center of interest in Richardson's approach is the derivation of consequences from clearly stated assumptions rather than a comprehensive explanation of what happens in international relations.

Accordingly, $x$ and $y$ are interpreted as the algebraic sums of positive and negative terms, namely, armament expenditures and trade volumes, respectively. In putting the model to a test by data from the arms race of 1909-14, these quantities are measured in gold units. (Later, when Richardson attempts to interpret the data of the succeeding arms races of 1933-39 and 1948-, he has to find a more reliable unit.)

We pass to the estimation of the parameters. Ignoring the grievance terms $g$ and $h$ for the time being, Richardson notes that the dimensions of $k, l, a$, and $\beta$ are all reciprocals of time and in our case are naturally interpreted: $a$ and $\beta$ are "relaxation rates," that is, they are indexes of how rapidly disarmament would proceed in the absence of the instigators of armaments, namely, the armaments of the other nation and the grievances. The order of magnitude of these parameters can be estimated from the actual disarmament rates after wars. From various data Richardson arrives at the following estimates: $\alpha=\beta=0.2$ or 0.3 per year. The parameters $k$ and $l$, on the other hand, are interpreted as the "apparent catching-up rates," that is, the rates at which the armaments of one nation would catch up with those of the other, provided that the other obligingly stood still. These depend on the war-industrial potential. Taking the German rearmament figures of 1933-36, when their potential opponents did practically stand still, these parameters for nations of Germany's potential also turn out to be about 0.3 per year. Richardson is now ready to examine the "classical" armament race of 1909-13, taking the principal powers on both sides of the impending conflict as those who unequivocally pledged participation, namely, France and Russia, on one side, and Germany and Austria-Hungary, on the other.

Assuming the co-operative components (trade) constant and the armament expenditures variable, he sets $x=U-U_{0} ; y=V-$ $V_{0}$, where $U$ and $V$ are armament expenditures and $U_{0}$ and $V_{0}$ are trade. He then obtains, from equations (XII) and (XIII), 


$$
\begin{gathered}
d(U+V) / d t=(k-a)\{U+V \\
\left.-\left[U_{0}+V_{0}-(g+h) /(k-a)\right]\right\} .
\end{gathered}
$$

That is, the plot of $U+V$ against the rate of change of $U+V$ ought to give a straight line. Moreover, the slope of this line ought to be $k-\alpha$ and the intercept

$-(k-a)\left[U_{0}+V_{0}-(g+h) /(k-a)\right]$.
Germany alone, and $\alpha$ is taken to be 0.2 , as previously independently estimated, the slope of the line, too, is in close agreement with the theory.

Let us now see what it would have taken in the light of this theory to prevent the arms race. For $d(U+V) / d t$ to vanish or to become negative, one must have the total

TABLE 8

DEFENSE BUDGETS IN $£ 10^{6}$ STERLING

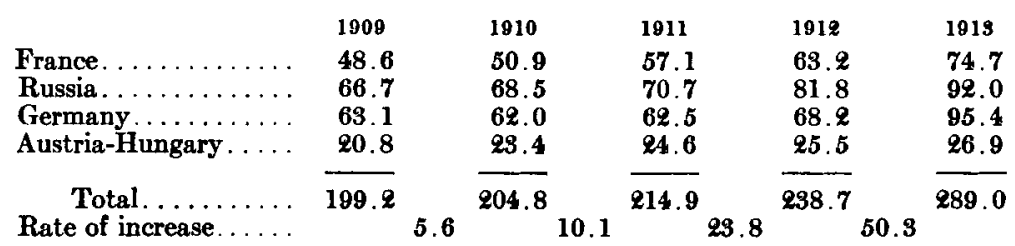

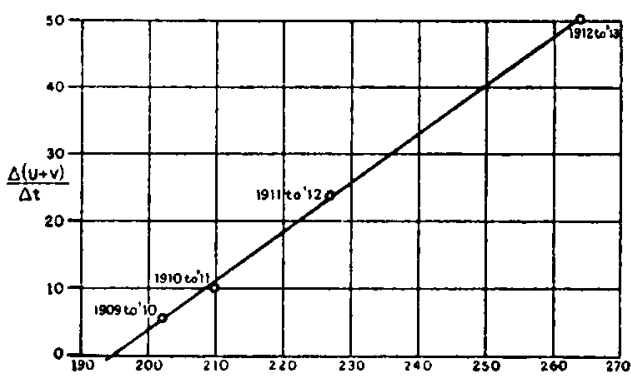

Fig. 7.-Rate of increase of total armament expenditures versus expenditures in the arms race preceding World War I.

The approximate magnitudes of $k$ and $\alpha$ have, we have seen, been independently estimated; $U_{0}$ and $V_{0}$ can be directly obtained from trade statistics; $g$ and $h$ are unknown. So the checks on the pragmatic validity of equation (XVI) are (1) the goodness of fit of the straight line to the data on expenditures and their rate of increase and (2) the agreement between the estimated value of $k-\alpha$ and the slope of the line.

The results are given in Table 8 and Figure 7. The goodness of fit leaves nothing to be desired. The slope of the line is 0.73 . Hence, if the war potential of both sides is taken at 0.9 , that is, three times that of volume of trade between members of the opposite sides of the coalition at least equal to the arms expenditures (ignoring the unknown grievance terms). That is, in 1909 a volume of at least $\& 199$ million sterling was required. In point of fact, that volume was $\& 171.8$ million sterling.

There are, of course, serious shortcomings of the theory even in this simplest "classical" case. For instance, the volume of trade between the potential combatants did not remain constant between 1909 and 1913 but increased. Therefore, the slope of the line should have decreased. On the other hand, the total trade volume, at almost all times, remained below the total armament expenditures. (The year 1911 was an exception, trade having exceeded armament expenditures very slightly. We must remember, however, that we have neglected the grievance terms, which could be supposed to compensate for this discrepancy.) So, at least qualitatively, the conclusions of the theory are not refuted by the data.

It cannot be emphasized too strongly that each conclusion in a theory of this sort is only a jumping-off place for further investigations. In no sense can the cited agree- 
ments between predicted and observed quantitative relations be considered corroboration of the theory. There is always the possibility that the instances of agreement are selected instances, even if the investigator is scrupulously honest. For example, in the above result, why are Great Britain and Italy omitted from the arms race? It can be argued, of course, that Britain was not so definitely committed to the Alliance as France and that Italy was ambivalent. Suppose, however, the data on the four principal powers were at wide variance with the theory and suppose the inclusion of Italy and Britain eliminated the discrepancy. Could it not be argued (alas, in retrospectl) that they should have been included?

Thus the encouraging and in some cases remarkable agreements between theory and experiment should not be taken seriously. They should be taken for what they areencouragements to develop the theory further. Two principal tasks face the "mathematical historian," namely, the construction of further theoretical models and the translation of raw historical data into quantitative variables. There is an embarrassment of choices in each of these tasks. The construction of models involves the choice of assumptions, and, unlike the physicist, who is often both guided and restricted in his choice of assumptions, the builder of a mathematical social science must virtually pull assumptions out of his hat. A similar ambivalence of proper choices besets with difficulties the problem of translating data into variables.

Richardson's work on arms races proceeds along both directions. He offers, besides the linear two-nation model described, a great number of other such models. Each determines a dynamic system. The problem of solving these systems, that is, of determining all the relevant variables as functions of time or of each other, though often of prodigious difficulty, is a straightforward math- ematical problem. The technical difficulties could well be overcome by judicious use of modem mathematical technology, which Richardson did not yet have at his disposal. Mathematical difficulties are therefore not the stumbling block on the road to a mathematical social science. The real difficulty is in deciding which, if any, of the wide variety of models are worth developing and studying intensively. To put it another way, the problem is to decide which is the fruitful direction of generalization.

One might, for example, make the twonation (or two-coalition) model somewhat more sophisticated by the introduction of non-linear terms. Several such models are offered by Richardson in the "theory of submissiveness." This theory is a modification of the linear theory described above, in the sense that the mutual stimulation coefficients $k$ and $l$ become functions of the balance of strength between the two nations (say of the difference or of the ratios of their armaments). This model provides for the "intimidation effect." When the discrepancy of strength becomes too great, the weaker nation buckles under and reverses the trend. This seems to be qualitatively the assumption underlying the policies of the great powers. Richardson's mathematical treatment allows him to combine this assumption with the previous ones, where the armaments are mutually stimulating. Once more, the advantages of mathematical treatment are emphiasized. Whereas adherents of verbal theories may engage in desultory arguments about whether shows of strength are conducive to peace or war, the builder of a mathematical theory can combine both assumptions (seemingly contradictory when stated in ordinary language) and reduce the question to one about the relative effects of the one and the other tendency.

Being non-linear, the submissiveness equations are difficult to solve explicitly, 
and always the question looms as to how worthwhile is the effort of working out the details; when this job is done, the prodigious one still remains of seeking out situations to which the equations can be hoped to apply.

On the other hand, other directions of generalization clamor for attention, for example, the extension of the number of rival blocs to more than two. Richardson undertakes this task also and derives some consequences (largely concerning stability conditions) for a system of $N$ nations. Space does not permit a detailed consideration of this theory. We note only that it is analogous to the theory of stability of mechanical and electrical systems. It would seem that the most useful results of such a theory would concern the relative importance of the various parameters, which, when given interpretation in social-economic-political terms would permit at least a qualitative theory and indicate where to look for corroboration or refutation.

The other task, as we have said, is the search for the significant variables. For example, after 1933, the gold unit becomes all but worthless in estimating the magnitude of expenditures. Moreover, the wide discrepancies between the economic systems of the U.S.S.R. and the other powers make expenditure figures extremely difficult to compare. Finally, the reliability of the official budgets, especially of the totalitarian states, becomes tenuous. In his search for a meaningful economic unit, Richardson finally settles on the "warfinpersal," the relation between per capita military expenditure and the salary of a semiskilled engineer. The cogency of his reasons for his choice is for economists to evaluate. At any rate, the function of the mathematical theory in instigating a search for significant units and variables becomes apparent from a perusal of Richardson's monumental efforts to make sense of the relations between economics and international politics. It all boils down to this: somewhere there are significant indexes of large-scale human behavior. The task is to discover these indexes and to find significant fundamental relations among them. Once these are found, one can attempt theories which enable one to derive gross aspects of observed behavior from a few relatively simple assumptions. This is the scientific method in a nut shell. The contribution of Richardson and others inclined toward mathematical theorizing is in showing that it does not matter where the cycle of observation-hypothesis-theory-verification begins. It may be at times useful to begin with theory in abstracto and at other times with the compilation of data. The cycle must be traversed several times anyway before a coherent picture can arise. One suspects that questions of scientific strategy have no general answers. Different situations and, significantly, different scientific temperaments call for different approaches.

\section{War Moods (9)}

Is war like a football game? Like a game of chess? Like a disease? People can always be found who will prefer each of these similes. What they will abstract depends on what part they themselves may have played in wars, on their temperament, on their cultural background, and on the century in which they live. Because of some sort of continuities and discontinuities which we perceive, we classify events. Accordingly, the maneuvers of armies in eighteenth-century Europe and the events of 1939-45 are both called "wars"; outbreaks of chicken pox and of the bubonic plague are both called "epidemics"; the events in Salem, Massachusetts, in 1693, those on the New York Stock Exchange on October 29, 1929, and those related to the acclaim of popular singers are all cited as instances of "mass 
hysteria." Perceived similarities often reside in the perceiver.

A mathematical investigation of such instances of mass behavior often places at the center of interest a behavior pattern whose most salient characteristic is that it is transmissible without having to obey a conservation law, that is, a pattern is acquired upon contact, without necessarily being given up by the transmitter. Epidemics, fads, rumors -all come under this category of mass behavior. The content of what is transmitted or its importance or triviality is, of course, immaterial to the mathematician except to the extent that it determines certain properties of the transmission process. Thus, in setting up his equations, the mathematician may want to know:

1. Is the transmission instantaneous upon contact, or is there an incubation period?

2. Is it necessary to consider differences in susceptibility?

3. Is the carrier contagious throughout the time he is infected (or converted)?

4. Does the degree of contagion depend on the total time of the process (the age of the epidemic) or on the time since contagion of each carrier?

5 . Is there immunity?

6. Are carriers being removed from the population, say, by the passing of the contagious period, by recovery with immunity, by quarantine, or by death?

The particular assumption made with respect to each of these questions determines the mathematical model, quite regardless of the content of the process. Thus, in terms of the underlying mathematical model, the appearance of a popular pianist and the outbreak of a war may have very similar effects on a population, even though the content of their behavior may be very different.

The basic model, then, assumes that each member of a large population can be in one of at least two states. Fundamental to the contagion model is the passing of an individual from one state to another because of contact with an individual in the second state or, more generally, with an individual in some third state. Except for this specific condition (the essence of contagion), the process has many degrees of freedom. For example, the number of states may vary; the states may be reversible or irreversible; the questions listed above may each be answered in different ways.

Richardson begins to construct his warmood model on the basis of just two mental states: for and against the prosecution of the war. Admittedly, reliable data or even a precise definition of these moods is extremely hard to come by. Yet, by gathering a great many impressions from a variety of sources, Richardson is able to arrive at a crude quantitative picture of war moods in Britain and in Germany immediately before, during, and immediately following the war of 1914-18.

In Britain there is very little evidence of overt war-mindedness during the period immediately preceding the murder of Archduke Ferdinand at Sarajevo. Only isolated outbreaks of hostility and occasional mentions of the trade rivalry between Britain and Germany are found in the press. The main preoccupation of this period seems to have been with Irish affairs.

The picture changes drastically immediately after Austria's ultimatum to Serbia (July 23, 1914). Still there is considerable resistance to Britain's participation in the war, especially in the leftist press. The invasion of Belgium (August 2) brings another drastic change. Opposition to war all but collapses. The vote in the House of Commons carries the declaration of war by 94 per cent. Only two of twenty ministers resign ( 10 per cent protest against the war?). Irish nationalists offer their support, etc.

The prowar peak is reached probably 
around the turn of the year. Thereafter "war-weariness" begins to set in, quite slowly at first but making itself felt by the beginning of 1917, when voices begin to be raised in favor of a negotiated peace. The by-elections in early 1917 are also indicative. In one, the antiwar candidate reported by the London Times as "absent from the contest, being now in custody of the military authorities," received 23 per cent of the votes. However, two other by-elections held soon afterward gave the antiwar candidate only 7 per cent of the votes. Still, by the spring of 1917, war-weariness was observ-

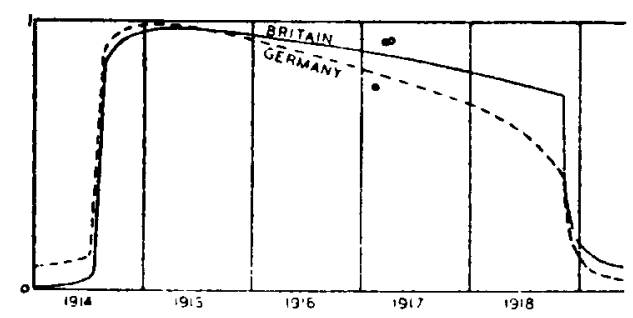

FIg. 8.-Richardson's conception of the war moods in Britain and Germany during World War I. The ordinate represents the fraction of the population overtly in favor of war. The circles mark the British by-elections.

able by the naked eye, which it had not been in early 1915. It increases steadily throughout 1917 and 1918 (various symptoms are listed by Richardson). The armistice brings a sharp discontinuity analogous and opposite to that noted at the declaration of war. The "Hang the Kaiser" movement persists as an aftermath, but soon this too dissolves, and overt war-mindedness sinks to almost its prewar level.

Germany shows a similar picture with minor but significant differences. There is evidence that the initial (prewar) fraction of the war-minded was somewhat larger than in Britain, as manifested in the overt praise of war as an institution (quite aside from war aims) by members of the professional military class (the Junkers). Bernhardi's book, Germany and the Next War, published in 1912 is also significantly revealing in this respect.

The unanimity of Germans immediately following the outbreak of the war was probably as complete as any nation has ever experienced. However, the war-weariness process sets in just as inexorably as in Britain and, indeed, accelerates more rapidly. The milestones listed by Richardson are (1) a recognition by the Prussian Ministry of War that disaffection is spreading (1916); (2) the vote in the Reichstag favoring negotiated peace by 214 against 116 votes (July, 1917); (3) recognition by the Crown Council of the futility of further offensives (August, 1918); (4) the appeals by the German Supreme Command for armistice, directed at the German government (September, 1918); (5) the appeal by the German government to President Wilson (October 3,1918$)$; (6) the mutiny of the German fleet (October 29, 1918). "Yet," Richardson concludes, "the armistice of November 11,1918 , certainly was not in accordance with the wishes of all Germans. Hitler, in particular, was furiously indignant."

Therefore, a residual war-mindedness following the armistice must be recorded. Richardson offers the graphs in Figure 8 as representing in semiquantitative fashion the time course of war-mindedness in Britain and in Germany during that interval.

One observation of Richardson's deserves special emphasis at this point. He cites a possible objection to this sort of treatment of war moods (that is, treating it like a disease that runs a regular course), namely, that war moods must be considered with reference to the particular peace terms offered at the moment. Richardson dismisses this objection outright. His thesis is that there are no rational components in war moods and that therefore the disease model 
with its regular, almost predestined, course is the proper one. Here we have, by implication, a rejection of the rational models of human conflict behavior, such as are offered, for example, in the theory of games. Indeed, the theory of games, on the one hand, and the deterministic theories of mass behavior, such as those of Richardson and Rashevsky, on the other, stand at the opposite poles of mathematical theories of human behavior. We shall have more to say on this topic below.

In his mathematical treatment, Richardson postulates not two war moods (for and against) but five. Each is a superposition of a conscious, overt mood on an underlying subconscious one. Thus he assumes that in times of peace the prevailing mood toward the potential opponent in the population at large is friendly with no underlying hostility. He symbolizes this situation thus: friendly: friendly. The start of an arms race, however, results in the accumulation of subconscious hostility until the prevailing mood becomes friendly : hostile. At the outbreak of hostilities, the hostile mood becomes overt, and the friendly components are driven into the subconscious: hostile : friendly. During the attrition phase of the war, war-weariness creeps into the subconscious region, so that there is a constant increase of the configuration hostile : war-weary. The next sudden change is the overt manifestation of warweariness, resulting, as in the outbreak of hostilities, in the reversal hostile : war-weary $\rightarrow$ war-weary : hostile.

Richardson bases this double-storied mood model on two types of considerations. One stems from a simplified version of depth psychology (or from psychoanalysis), where the overt behavior is a manifestation not of the total personality but only of the "party

4 The first adjective of each such pair represents the overt mood, the second the covert mood. in power" at the moment within the person. The transformation of behavior into its opposite may seem mysterious if only overt behavior is considered, but ceases to be so if we take into account the accumulation of power of the "opposition," which presumably takes place in the subconscious and is able to "take over" at some propitious moment, just as is observed to happen in the political life of states.

The other sources of Richardson's considerations are mathematical. $\mathrm{He}$ is at a loss how to explain the very sudden shifts of war moods especially at the outbreaks and the cessation of hostilities as contrasted with the more or less continuous gradation between the arms race and the war. Richardson states that he sought in vain for a natural mathematical explanation for the sudden changes at these transition points and could find a satisfactory answer only by postulating the double moods.

It is not clear whether Richardson is saying that he could not make his mathematical models exhibit threshold or "ignition" phenomena. If so, this is surprising, because such effects are quite common in just such equations as Richardson postulates for his war-mood contagion effects. ${ }^{5}$ Indeed, in citing the papers of Kermack and McKendrick, (1), which inspired his contagion model, Richardson mentions just such threshold effects of epidemics.

To be sure, such explosion-like effects are found only in non-linear systems (classical examples are known as "relaxation oscillations"), but then the contagion systems treated by Richardson are non-linear. At any rate, the double-mood model is introduced by Richardson both because it harmonizes

5 Cf., for example, the mathematical models of mass imitative behavior in N. Rashevsky, Mathematical Biology of Social Behavior (Chicago: University of Chicago Press, 1951 ). 
with certain psychological views and because it enables him to introduce threshold effects ad hoc into this equation.

We continue to pursue Richardson's argument. $\mathrm{He}$ assumes that the transformation friendly : hostile $\rightarrow$ hostile : friendly, that is, the transformation characteristic of the outbreak of overt hostility is hardly ever directly reversible. Here is an interesting analogy with chemistry. It is as if a molecule or an atom could exist in two crystalline states, one more stable than the other. No theoretical reason is given for this bias. The evidence cited has to do with various unsuccessful attempts to turn the tide of war after it had started-attempts which were always futile at the early phases but which commanded increasing attention as the war ran its course, that is, as the war moods went through the successive changes. In Richardson's estimation the transformation back to the friendly mood takes place only via the long, tortuous path of war-weariness. The passage to overt hostility is a matter of days; back to submerged hostility a matter of years, while the (presumed) disappearance of underlying submerged hostility is a matter of at least a generation.

The argument is, of course, far from rigorous, and one wonders whether this interpretation, admittedly plausible as applied to the outbreak of World War I, applies in general. The "typical" manifestations of war hysteria took place in France, Germany, Austria, Serbia, and to some extent in Russia in August, 1914, and in the United States in April, 1917. Here "typical" is used not in the sense that the phenomenon was historically common but in the sense that it best fits the theoretical description offered. The events of September, 1939, in Europe and even those of 1941 in the United States and in the U.S.S.R. in similar circumstances were not, at least overtly, of the same kind. People did not kiss each other in the streets in
France when war on Germany was declared in 1939, the way they did in 1914. The mood in Britain, too, was much more somber in 1939. The population of the United States on December 7, 1941, and that of the U.S.S.R. on June 22, 1941, seemed more shocked than elated. In the case of Britain and France, the intensification of hatred for the enemy in World War II seemed much more gradual than in World War I. To begin with, there seemed to be much more of this hatred before the outbreak of the war and the steep rise in the case of both countries seemed to occur not immediately at the outbreak but considerably later, after defeat in the case of France and during the aerial Blitz in the case of Britain. Evidence of just the kind cited by Richardson for World War I can be cited to support the estimates above. For example, voices for negotiated peace were much stronger and received more favorable attention in Britain in 1939 than later, when Britain fought alone. ${ }^{6}$ In the U.S.S.R., too, hatred for the enemy grew steadily in intensity throughout the war in response to the atrocities of occupation.

One might also argue that the outbreak of war hysteria in Russia in 1914 was confined to the city population. People indeed "kissed each other on the streets" in cities, but the peasantry (comprising over 80 per cent of the population) seemed untouched. The attitude of the peasantry has been summarized in the phrase, "We are from the Tambov province; the Germans won't come this far."

It is possible that these very different manifestations can be accounted for by differences in the values of the parameters which enter Richardson's equations. But it is also likely that Richardson's model applies not generally to war-mood dynamics but to

6 Cf. W. Churchill, The Second World War (Boston, 1948-53). 
certain types of mass-hysteria dynamics of which particular war moods may or may not be special cases. Indeed, it may be pointed out that the "typical" 1914 outbreak is an almost unique example of its kind. Possibly the mood in Japan in 1905, following the attack on Port Arthur, that in Germany in 1870 , and that in Britain at the outbreak of the Boer War resembled 1914 in the initial stages, but evidence for the onset of warweariness is difficult to find in those cases.

Another possibility is that the conditions which make for the war-mood picture described by Richardson, especially its initial phases, are to be sought not in general mass psychology but in certain special circumstances. Nationalism, we are told by some historians, is not a permanent feature of social organization but a stage. It is possible to trace the growth of national consciousness, particularly in Europe following the breakup of the feudal system. It may also be possible to trace its decline in Europe following 1918 except for secondary flareups in some totalitarian states. The coincidence of mass hysteria with the outbreak of a war may be typical only at times when a peak of national consciousness has been reached. What this means is a psychological question. The translation of such questions into mathematics may be possible but may necessitate an altogether different treatment.

The reservations we have listed do not detract from the importance of Richardson's theories but point to a different direction of generalization, namely, not to a theory of war moods but to a theory of mass hysteria, where the term "hysteria" is to be stripped of its morbid connotations (perhaps a less loaded term should be introduced) and to be endowed instead with a mathematical meaning referring to its purely dynamic properties, rezardless of content. It may be that fads, with their suddenness of outburst and with their typically gradual declines fol- lowed by almost as sudden disappearance, are much more frequent manifestations of Richardson's model than war moods.

Let us now return to the mathematical treatment of Richardson's model. We shall follow his war-mood interpretation, keeping in mind, however, our reservations about its general applicability in this context.

At any moment the population whose attitudes are the subject of the study are divided into five classes, each class characterized by one of the double moods described above. The Greek letters denote the fractions of the population in the respective classes. Thus

$\beta=$ The fraction in the mood

friendly:friendly,

$\xi=$ The fraction in the mood

friendly: hostile,

$\eta=$ The fraction in the mood

hostile: friendly,

$\rho=$ The fraction in the mood

hostile:war-weary,

$\omega=$ The fraction in the mood

war-weary: hostile.

In addition, we have a fraction which has died as a result of the war, denoted by $\theta$. Thus

$$
\beta+\xi+\eta+\rho+\theta+\omega=1 . \quad(\mathrm{XVII})
$$

Subscripts on the letters (for example, $\beta_{1}$ ) refer to the respective nations; asterisks to the absolute numbers. Thus, if $N_{1}$ is the population of the first country, then

$$
\beta_{1}^{*}=\beta_{1} N_{1}
$$

(XVIII)

The first process considered is a conversion from $\beta$ to $\xi$, that is, the "latent" infection by subconscious hostility, which pre- 
sumably pervades the population in the initial stages of conflict prior to the outbreak of hostilities. Note that the growth of $\xi$ will not necessarily be observable by ordinary methods. In the terminology of epidemics, $\xi$ is the fraction of the susceptible. To use another analogy, the accumulation of $\xi$ is like the accumulation of heat in a process leading to spontaneous combustion. Or, to use still another analogy, it is like the decline of potential difference between the inside and the outside of a nerve prior to the critical moment when the difference becomes less than a threshold value and the self-propagated "action potential" (the reverse of the resting potential) is instigated.

We said that $\xi$ may not be observable directly as war-mindedness. It may have, however, indirect manifestations, for example, in the progress of an armament race. In Richardson's treatment the growth of armaments of the opposing side is the stimulant of the growth of submerged hostility in the population of the country in question. The equations governing the growth of warmindedness are therefore analogous to those governing the growth of armaments. In the simplest case of no restraint, we have, as in a similar situation related to arms races,

$$
\frac{d \xi_{1}^{*}}{d t}=K \beta_{1}^{*} \xi_{2}^{*}=\frac{-d \beta_{1}^{*}}{d t}
$$

The last equality shows that $\xi$ grows at the expense of $\beta$. This equation is modified by including the effect of the overtly hostile in the prospective enemy nation. Thus, expressed as the depletion of $\beta$, the equation becomes, in absolute numbers,

$$
\frac{-d \beta_{1}^{*}}{d t}=-K \beta_{1}^{*}\left(\xi_{2}^{*}+W_{12} \eta_{2}^{*}\right)
$$

$W_{12}$ being another constant.

This equation is none too satisfactory, implying as it does that $\beta_{1}$ would always de- crease as long as $\xi_{2}$ and $\eta_{2}$ were positive in the other nation. To account for restoring influences, Richardson subtracts a constant $A^{\prime}$ from the terms inside the parentheses on the right side of equation (XX), arriving at

$\frac{-d \beta_{1}^{*}}{d t}=K \beta_{1}^{*}\left(\xi_{2}^{*}+W_{12} \eta_{2}^{*}-A^{\prime}\right)$.

There is still trouble in the sense that the disappearance of hostility in the opposing nation would make for unlimited growth of the friendly population (beyond the total population). So "buffer" terms must be introduced. In its final form, Richardson puts, for the rate of change of $\beta$ (using fractions now),

$$
\begin{aligned}
\frac{d \beta_{1}}{d t}=\beta_{1}[ & A_{1}\left(\xi_{1}+\eta_{1}\right) \\
& \left.-K_{12}\left(\xi_{2}+W_{12} \eta_{2}\right)\right] .
\end{aligned}
$$

Stated in words, the mathematical meaning of this equation is the following. The rate of growth of $\beta$ is enhanced by the proportion of covertly and overtly hostile in the own population, and its decline is enhanced by the portions of overtly and covertly hostile in the other population. Moreover, the absolute magnitude of the rate of growth of this fraction is proportional to the fraction itself.

In Richardson's interpretation, the depletion of $\beta$ (a measure of concentration!) is proportional to the weighted differences between the hostile of both kinds in one's own and in the opposing populations, as if the presence of a large concentration of hostiles in one's own population mitigated the further increase of hostiles.

The plausibility of such an assumption may be argued both ways. We must point out, however, that equation (XXII) has another, perhaps simpler, interpretation in terms of the very same contagion model cited by Richardson. If conversion could go 
either way, then the $\beta$ could be recruited from the $\xi$ and $\eta$ when the latter came in contact with the $\beta$. This "recovery" (if we may interpret the thoroughly friendly state as "healthy") amounts to an anticontagion, unknown in ordinary contagious disease but possibly worthwhile considering seriously in the epidemics of moods. True, Richardson discounts the possibility of the transformation hostile : friendly $\rightarrow$ friendly: hostile, but explicitly only for the population as a whole. In chemical terminology, this could mean simply that the reaction coefficient in one direction is much greater than that in the other. In principle, therefore, we could admit contagion between any pair among the five moods. Moreover, as a result of contact between two classes, transformation could conceivably occur into a third class.

The complete system of equations given by Richardson is as follows:

$$
\begin{aligned}
& \frac{d \beta_{1}}{d t}=\beta_{1}\left[A_{1}\left(\xi_{1}+\eta_{1}\right)\right. \\
& \left.-K_{12}\left(\xi_{2}+W_{12} \eta_{2}\right)\right] \text {, } \\
& \frac{d \xi_{1}}{d t}=-\beta_{1} A_{1} \xi_{1} \\
& +\beta_{1} K_{12}\left(\xi_{2}+W_{12} \eta_{2}\right) \\
& -C_{12} \xi_{1}\left(\eta_{2}+\rho_{2}\right), \\
& \frac{d \eta_{1}}{d l}=-\beta_{1} A_{1} \eta_{1}+C_{12} \xi_{1}\left(\eta_{2}+\rho_{2}\right) \\
& -B_{12} \eta_{1}\left(\eta_{2}+\rho_{2}\right)-E_{12} \eta_{1}\left(\eta_{2}+\rho_{2}\right), \\
& \frac{d \theta_{1}}{d t}=E_{12}\left(\eta_{1}+\rho_{1}\right)\left(\eta_{2}+\rho_{2}\right), \\
& \frac{d \rho_{1}}{d l}=-D_{1} \rho_{1} \omega_{1}-F_{12} \eta_{1} \omega_{2} \\
& +B_{12} \eta_{1}\left(\eta_{2}+\rho_{2}\right)-E_{12} \rho_{1}\left(\eta_{2}+\rho_{2}\right) \text {, } \\
& \frac{d \omega_{1}}{d t}=D_{1} \rho_{1} \omega_{1}+F_{12} \rho_{1} \omega_{2} .
\end{aligned}
$$

The arguments which lead to these equa- tions are similar to those which led to the first of them and will not be reproduced here. We will note, however, some general features of the system and a few of its details.

The system is given for the country denoted by subscript 1 . The equations for the other country are of similar form but, in general, have the "reaction constants" of different values. Each equation is a differential equation of the first order and of the second degree. Each rate of change is a homogeneous quadratic form in the dependent variables. That is, each contact between members of a pair of classes contributes positively or negatively to the rate of change of a class. Constants with single subscripts denote the pairing of classes within the same cuuntry; those with double subscripts the pairing from different countries. Because of equation (XVII), the sum of the rates of change must vanish, and this is insured by the coefficients on the right.

Further we note that, although $\eta$ is recruited from $\xi$ of the same country (the second term in eq. $[\mathrm{XXV}]), \xi$ is not recruited from the $\eta$ of the same country, which reflects Richardson's assumption that the transformation friendly: hostile $\rightarrow$ hostile : friendly is not reversible. Apparently he takes this irreversibility to be absolute, though, as we have pointed out above, he need not. Nevertheless, the $\beta$ are recruited from the $\xi$ of the same country (the first term of eq. [XXIII]). True, in Richardson's interpretation this effect is interpreted as the result of a restraining influence, not as contagion (or "anticontagion," as we have called it), but its effect, as shown in the formalism of the mathematics, is exactly the same as that of contagion.

The dead are recruited from the overtly hostile, under the assumption that the overtly hostile are those who actually fight. Here 
is a serious weakness in the psychological assumptions. Are the most vociferous flagwavers always among the actual combatants? The contagion of overt war-weariness occurs both via own and via enemy carriers, as reflected in equation (XXVIII).

The system is non-linear and is not amenable to the powerful general methods of solution applicable to linear systems. Certain important aspects of non-linear systems have been studied, however. V. Volterra, in particular, in his theoretical studies on the interaction of species in predator-prey relations, has derived interesting general properties of non-linear systems of certain types. Richardson states, however, that his system cannot be subsumed as a special case of Volterra's. To be like Volterra's, Richardson's equations would have to include as a factor on the right side the variable whose derivative appears on the left, such as is the case in equation (XXIII), but not in the others. Accordingly, Richardson does not attempt to apply Volterra's method to his system but proceeds to investigate the properties of his system at certain critical phases, where simple approximate solutions can be obtained. These phases are listed as follows:

(i) an early phase of uneasy peace, in which $\beta$ is near unity but $\theta, \rho$, and $\omega$ are zero; (ii) the outbreak of hostilities, during which $\xi$ and $\eta$ are important but $\theta, \rho$, and $\omega$ are negligible; (iii) a middle phase of persistence and attrition, in which $\theta, \rho$, and $\eta$ are important but $\beta$ and $\omega$ can be neglected; and (iv) the cessation of hostilities at a time when $\rho$ and $\omega$ are important but the other variables can be neglected.

The earliest phase (i) allows the reduction of the general system (XXIII)(XXVIII) to a simple linear system of two first-order differential equations. In the initial phase all the population is assumed to be $\beta$ or $\xi$. Thus $\beta_{1}+\xi_{1}=\beta_{2}+\xi_{2}=1$, and we have

$$
\begin{aligned}
& \frac{d \beta_{1}}{d t}=\beta_{1} A_{1} \xi_{1}-\beta_{1} K_{12} \xi_{2}=-\frac{d \xi_{1}}{a t} \\
& \frac{d \beta_{2}}{d t}=\beta_{2} A_{2} \xi_{2}-\beta_{2} K_{21} \xi_{1}=-\frac{d \xi_{2}}{d t}
\end{aligned}
$$

(XXIX)

Moreover, the overwhelming majority are assumed to be $\beta$, so that the $\beta_{i}$ can be taken to be unity (that is to say, the quadratic terms resulting from the expansion

$$
\beta_{i}=1-\xi_{i}
$$

are neglected). We now have the linear system

$$
\begin{aligned}
& \frac{d \xi_{1}}{d t}=-A_{1} \xi_{1}+K_{12} \xi_{2}, \\
& \frac{d \xi_{2}}{d t}=K_{21} \xi_{1}-A_{2} \xi_{2} .
\end{aligned}
$$

(XXX)

This system is formally equivalent to that of the arms race discussed in Section IV and, of course, has the same sort of solution. Stability obtains if $A_{1} A_{2}>K_{12} K_{21}$ (the product of the coefficients of restraint exceeds the product of the coefficients of mutual stimulation). Otherwise, instability results, and the $\xi$ increase approximately exponentially. This situation cannot, of course, represent the complete system for very long, because the assumption $\beta_{i}=1$ soon fails to apply.

Next, Richardson combines his arms-race assumptions with those relating to the growth of (submerged) hostility and finds that the resulting arms-race model includes constant terms (cf. eqs. [XII] and [XIII]) previously interpreted as "grievance" terms. Also he finds that the conditions of stability for the arms race are consistent with those for their war-mood transformation. Both results are in no way surprising, since in 
Richardson's assumptions the arms expenditures are simply linear transformations of the submerged hostilities. Thus the first phase of war-mood dynamics is but another manifestation of the arms race both in the assumptions and in the conclusions, and the theory of war moods has nothing new to say at this point.

The second phase (ii) also yields to a simple and well-known mathematical treatment, especially in the "symmetric" case, where the fractions $\xi$ and $\eta$ (which are here assumed to account for practically the entire population) are equal in both populations. Under these extremely simplified conditions, the process reduces to that of simple contagion,

$$
\frac{d \xi}{d t}=-C \xi \eta=\frac{d \eta}{d t}
$$

That is, if $\eta$ represents the fraction of the sick (the carriers), the depletion of the uninfected will be proportional to the product of the fractions of the infected and the uninfected. The solution of equation (XXXI) is the well-known logistic equation,

$$
\eta=\frac{A e^{C t}}{1+A e^{C t}}
$$

(XXXII)

where $A=\eta_{0} /\left(1-\eta_{0}\right) \quad\left(\eta_{0}=\right.$ fraction of overtly hostile at the start of the process considered). The shape of the logstic curve is sigmoid. Whether the rapidly rising fraction of the overtly hostile near the inflection point can be called an "explosion," as implied by Richardson's description of the sudden transformation immediately preceding the hostilities, depends on the size of the constant $C$. Of this later.

The third phase (iii) again considered for the symmetrical war is characterized by the condition $\eta+\theta+\rho=1$. Here everyone is either overtly hostile, in one of the two forms of this mood, or dead. We then have

$$
\begin{gathered}
\frac{d \eta}{d t}=-(B+E) \eta(\eta+\rho) \\
\frac{d \theta}{d t}=E(\eta+\rho)^{2} \\
\frac{d \rho}{d t}=(B \eta-E \rho)(\eta+\rho) .
\end{gathered}
$$

In this system $(\eta+\rho)$ can be eliminated, and we have a single equation governing the growth of casualties in the attrition phase, namely,

$$
\frac{d \theta}{d t}=E(1-\theta)^{2}
$$

(XXXVI)

whose integral is

$$
\begin{aligned}
& \theta=1-\frac{1}{E t+A} \\
& A=\frac{1}{1-\theta_{0}} \cong 1
\end{aligned}
$$

in the initial stages, so that

$$
\theta=\frac{E t}{E t+1}
$$

(XXXVIII)

Here at last is a formula in principle directly verifiable by observation. However, this is only an illusion. We must keep in mind that the piecemeal "solutions" are solutions only in certain very short ranges of time, because of the approximations made. In these short ranges all solutions will be approximately straight lines. For example, according to equation (XXXVI) the increase of dead seems to be proportional to the square of the fraction of survivors in a symmetrical war, a straightforward and interesting relation. Its validity, however, is confined to the range where there are yet no overtly war-weary.

However, encounters between the hostiles 
of opposing nations contribute not only to the number of dead but also to the number of covertly war-weary (cf. eq. [XXVII]) and ultimately to the overtly war-weary, who, according to the equation (XXVI), do not contribute to the increase of dead. ${ }^{7}$ But in a range sufficiently small, any curve is approximated by a straight line. Therefore, the dependence of the rate of casualties on the square of the survivors cannot be put to a meaningful test.

Another formula derived from this approximation is

$$
\eta=(1-\theta)^{1+B / E} \cdot(\mathrm{XXXIX})
$$

That is, the decrease of the $\eta$ among the survivors, through the onset of war-weariness, is given as a function of the war dead. Again, this formula is almost impossible to verify, since, by definition, the difference between $\eta$ and $\rho$ is in the subconscious and cannot be assessed by any simple statistical methods. The formula allows us, however, by combining various assumptions and observations, to make a rough estimate of $B$. We shall presently see that the main value of these approximations is not in the opportunity they provide for testing the dynamic process but rather in the possibility of obtaining estimates of the parameters. We shall presently discuss the value of obtaining even the crude estimates of these parameters.

7 Here is another serious weakness in Richardson's assumptions. Are the overtly war-weary removed from combat? Also, why not make the number of dead contribute to the rate of growth of the war-weary, which does not appear in either equation (XXVII) or equation (XXVIII)? It can be easily shown that any number of alternative assumptions can be made with plausibility comparable to that of Richardson's assumptions. Of primary interest, therefore, are not the particular assumptions Richardson makes but the principal idea of his approach.
In the final phase (iv), we have

$$
\theta_{T}+\rho+\omega=1 \text {, }
$$

that is, everyone is either aggressive-warwearied, war-wearied-aggressive, or dead. The subscript $T$ means that $\theta_{T}$ is approximately constant (the fighting has petered out on the verge of the armistice).

Further,

$$
\begin{aligned}
& \frac{d \rho}{d t}=-(D+F) \rho \omega, \\
& \frac{d \omega}{d t}=(D+F) \rho \omega .
\end{aligned}
$$

This is again the logistic case, except that the dead do not participate in the changing war mood. The process is the exact reverse of that in phase ii.

It must be emphasized that the theoretical investigation just described is still far removed from the "testing" of the mathematical model proposed and so cannot be considered as a step in the cyclical process: observation-generalization-model construction-empirical test-modification of the model. This cyclical process, usually represented as the schema of "scientific method" is only a highly idealized conception of what takes place in the construction of a complex theory. We have seen, for example, that the differential equations presumably describing the dynamics of war moods are too complex to be solved in their general form and, in all likelihood, much too simple to be expected to give an even fair approximation of the real process. Such systems, therefore, are little more than "mental bridges" from the complexity of real phenomena to our attempts to understand them. The mathematical social scientist keeps reiterating the provisional character of such attempts. Indeed, a warning not to take such models for anything but first approximations has become an inevitable remark in the introductions to such work. 
To Richardson's credit, it must be said that he does try to make the next step, that is, the estimation of the numerical constants involved. We have seen how he approaches this task in the arms-race model. In the war-moods model, an attempt to evaluate the constants is important for another reason besides its significance in giving some content to the theory. A glance at the system (XXIII)-(XXVIII) shows that it is of a certain type, namely, the right sides are all homogeneous quadratic forms. With six variables, the most general such form would have 36 terms, and so the system of six equations would have 216 constants. These constants are not all independent, however, because of the conservation restrictions; counting the dead as belonging to the population, the population is assumed to remain constant during the process studied. These conservation restrictions bring certain symmetries into the matrix of coefficients. Since a great many models of contagion and bimolecular chemical reactions are of this type, it would be desirable to have a general theory of such systems, such as already exists for linear systems, where the right side is a square matrix. Even before a complete theory is developed, no doubt certain theorems will begin to appear, treating of some general properties (for example, stability properties) of such systems. Indeed, a considerable body of such theory already exists.

In the construction of the theory of "quadratic homogeneous differential equations" it is useful to examine the properties of specific systems of this sort where the numerical values of the coefficients are known. Mathematical technology now available (not available at the time Richardson did the bulk of the work here described) makes possible the explicit solution of any number of such specific systems. To make the system (XXIII)-(XXVIII) specific, we must know the numerical values of the co- efficients. Once these are established, highspeed computers can reveal to us the dynamic behavior of the system. We can then engage on a program of "mathematical experimentation," for example, see how sensitive the behavior of the system is to changes in the various parameters. Since all these parameters acquire in a specific system social-psychological meanings (either as contagion parameters or, as Richardson prefers to interpret some of them, as parameters of restraint and of mutual stimulation), we can start to build theories of mass behavior in which the stability of mass behavior is related specifically to such parameters, however interpreted. Then and only then can the methodological cycle of hypothesis-prediction-comparison-modification of hypothesis begin. In this way we could get around the almost impossible task of fitting a highly complicated model to perhaps hopelessly complex situations. It is not the exact behavior of a real system which we would seek to predict by these methods but its more general properties.

The situation is no different in applied physical science. The non-linear systems which characterize problems of aerodynamics and of complex mechanical systems are seldom solved in the general case. Solutions are obtained for special cases where numerical values of the parameters are known at least approximately. Much use is made of analogical physical models (for example, wind tunnels, etc.). From a great number of such numerical solutions some general properties of such systems are sometimes discernible. Richardson's researches suggest that a similar procedure is indicated in the study of social dynamics.

\section{Critique}

How is a scientific investigation to be evaluated? One suspects that there are several factors which determine the "worth" of 
a scientific endeavor, but attempts to identify them do not hold any more promise than attempts to identify the factors which make a literary or an artistic work great or trite. As extreme examples, take two investigations, both highly admired in the scientific circles where they are understood but whose virtues are practically incomparable: Mendel's discovery of the segregation of inherited characters and of statistical laws of inheritance and Gauss's calculation of the orbit of Ceres. The former, buried for thirtyfive years and subsequently rediscovered, is cited as a milestone in biology, a gateway to the vastly fertile field of genetics. No remotely similar claims can be made for the latter. On the other hand, Gauss's feat is hailed as an ultimate achievement of mathematical virtuosity, an overcoming of seemingly insuperable diffculties and thus a triumph of human intellect. Certainly no such claims can be made for Mendel's achievement, almost homely in its modesty. It would seem that these two endeavors are admired for opposite reasoñs. At times parsimony has been offered as a criterion of scientific significance. If parsimony is taken as a ratio of the extent of the results to the complexity of the means, Mendel's work would certainly rate high on that scale, but Gauss's would rate very low. Gauss's means were enormously complex, while his result was to find a clod of dirt that had eluded the telescopes. Science would hardly have suffered if Ceres were never found again.

We bring these illustrations to warn against facile comparisons of scientific achievements by preset standards of value. Such comparisons will, nevertheless, continue to be made. Our warning concerns the danger of taking them to be decisive.

With this reservation in mind, let us first develop the most severe criticism to which Richardson's work is vulnerable. After this job is done, we can look for its positive value.

Richardson applies to certain aspects of human behavior, particularly mass behavior: the tools of classical mathematical analysis: the calculus and differential equations. These are techniques. But behind the techniques is an elaborate metaphysical orientation. It is most important to note that this orientation is not the only possible one even within the framework of the mathematical approach. This will be made clear when we describe alternative approaches. Since there are several mathematical approaches to a set of phenomena, it is possible to raise the question of the applicability or the efficacy of each.

The view of the world which leads an investigator to use classical analysis pictures all events as imbedded in some sort of continuum. Thus every event can be described by an $n$-tuple of real numbers, one of which is time. Time keeps flowing along, and, as this co-ordinate changes, the other components of the $n$-tuple also change. Thus at all times one has not only the "state of the world," that is, the totality of all such $n$-tuples, but also their rates of change. Next it is supposed that these co-ordinates and the rates of change are connected by mathematical relations. The business of the investigator is to discover these relations. Once they are discovered, the How of events can, in principle, be deduced, that is, the $n$-tuples which constitute the events become known functions of time, and so, simply by looking at the "clock," the successful investigator should be able to guess the "state of the world." This is the essence of mathematicophysical determinism. This is the framework of thought which has proved its tremendous power in classical physics and to some extent in chemistry. For the solar system is "explained" if all the positions of all the planets are deduced as functions of time 
from the few relations involving these positions, their rates of change, and the masses. A chemical reaction is "explained" if the concentrations of the substances involved are similarly deduced. The mathematical economist, too, works in the same metaphysical framework, except that his variables are different sorts of observables: prices, production rates, tax rates, interests, employment, etc.

This is the framework in which Richardson predominantly worked. His variables were again different: armament expenditures, trade volumes, numbers of people in this or that psychological state, war casualties, etc. But the underlying assumptions were always of the same kind: postulated nathematical relations among these quantiies and their rates of change.

Now let us go back to a time before this sort of thinking became second nature to nathematical scientists. There was a time when the notions of "function" and of "rate of change" were lacking from the mathenatician's repertoire. Yet certain branches of mathematics were developed to extreme$y$ high degrees of sophistication even by nodern standards. Geometry was profound ind subtle. Many deep properties of numsers were discovered by ingenious reasonng. The notion of what constitutes proof was almost as rigorous as it is today. In pite of Newton's tour de force (he used he methods of classical geometry in preienting his celestial mechanics to the world), $t$ is now clear that all that mathematics vould be of no avail in modern physics. The most intricate relations among various zeometric figures, the most startling contructions with ruler and compass, the ultinate in ancient mathematical skill, would ot be of any use in problems concerned vith the spread of heat through a body or vith what goes on in an alternating current ircuit. On the other hand, such statements as "the rate of change of the sine function is the cosine function," which is of fundamental importance in the problems mentioned, are entirely beyond the scope of ancient mathematics. They had no language in which to express such ideas.

This is what we mean when we say that ancient mathematics is not applicable to classical physics. It cannot even be extended to become applicable, unless, by extension, one means the introduction of totally new concepts, a reorganization of thinking about quantities, relations, etc.

Now let us turn the tables on classical analysis and ask, "To what extent is classical analysis (admirably suited to classical physics) applicable to theories of human behavior?" Is it possible that it lacks necessary concepts, in the sense that ancient mathematics lacks certain concepts necessary for physical theory? If so, then no amount of development of the techniques of classical analysis will break the barrier which separates its range of applicability from that of human behavior. There are certain technical difficulties inherent in Richardson's approach, for example, the lack of general methods of solving non-linear differential equations. These difficulties can be overcome. But if the weakness of the method is in the paucity or in the irrelevance of its fundamental concepts, then the resolution of the technical difficulties will be no help.

Similar considerations apply to the empirical side of Richardson's study. The problem here is to choose the important variables and to gather the data pertinent to them. Admittedly, the gathering of the data is beset with difficulties. But, even if the difficulties are overcome, one may still be on the wrong track if the variables one has chosen are not the important ones, if, say, the things to look at are not pounds sterling or even "warfinpersals," but, say, metaphorical identifications made in the minds of 
certain people with respect to war, whether they view war as a sport, a necessary evil, a rejuvenating tonic to combat decadence, or a vehicle for missionary zeal. A priori, one does not know. Therefore, several possibilities must be kept in mind.

Is there evidence that the approach through an analogy with physics, chemistry, epidemiology, or, to take the complexity of the phenomena into account, with meteorology is a sterile one? No, there is no direct evidence of this sort, but there is always a possibility. An analogical argument, however, can be made. Because it is merely analogical, it cannot, of course, be conclusive. Suppose a man from Mars began a quantitative investigation of all the chess games played on earth. He would carefully plot the rate of attrition of the pieces, the frequency distributions of the lengths of the games, correlations between various types of capture, distances traveled by bishops, rooks, and queens, etc. If he did this for very many games, he would certainly discover regularities: the law of large numbers would operate here just as in human affairs. He could even establish relations among these regularities, such as the distance traveled by pieces as a function of the number of pieces on the board, etc. He could then predict what the time course of these variables would be if averaged over many games. He could conceivably develop a fullfledged mathematical science of what he thought was chess. And yet he would have no idea of what for the chess player is the essence of chess. The chess player, on the other hand, also has a "science." It is not an exact science, because intuitive notions still play an important part in it, but it is to some extent a science, and it is far more relevant for the "essential" features of the game. The chess player's science contains concepts absent from the conventionally quantitative approach of the Martian-con- cepts like "offensive," "defensive," "pressure," "mobility," "strategy," "control," even "elegance." It is possible that these intuitive notions of the chess player can be translated into measurable quantities, but the opposite process is unlikely: it is not to be expected that notions pertinent to the real problems of the game would occur to any who contemplated only the obviously observable quantities.

Let us return to our discussion of various frameworks of mathematical thought. We have already mentioned two-the classical geometry of antiquity and the classical analysis of yesterday. The developments of the present century have struck out in still another direction, typically represented by abstract algebra and topology. A characteristic feature of modern mathematics is that "number" or "magnitude," as conventionally understood, is not at all central to it. Of particular interest to the mathematically inclined social scientist is the so-called "mathematical theory of games," developed entirely in the new spirit. It would be extremely difficult to explain to a non-initiate just how this recent theory has enhanced the understanding of the essentials of the game of strategy by considering matters far transcending the content of any specific game. The notion of "strategy" as it appears in game theory is mathematically exact; yet it contains the really relevant aspect of what any player of strategic games calls "strategy." By an analysis of this and related notions, the mathematical theory of games goes to the very heart of all situations in which people having partially conflicting, partially coinciding, goals match wits.

Curiously, a mastery of game theory would hardly make anyone a better player in any particular game. The techniques of the various games are absent from the theory. But the concepts of the theory are extraordinarily rich and lead to wholly un- 
expected insights. To give an example, it becomes plain in the light of game theory that chess and tic-tac-toe are more closely related than tic-tac-toe and "matching pennies." It is also possible to assert that in some respects "matching pennies" is a more complex game than chess (since it requires the notion of "mixed strategy," which chess does not), etc. Such conclusions may seem absurd, but we must remember that the assertion of the biologist that a mouse is more like a whale than like a frog seems absurd to anyone ignorant of biology, and yet this assertion contains a profound truth.

We have used the example of game theory to illustrate the appearance of a mathematical discipline with entirely new concepts, which may be the very concepts required in a mathematical treatment of human affairs. Being a "modern" branch of mathematics, game theory deals with entities which are not typically magnitudes or functional relations among them. The basic entities of game theory are "sets." The assertions of the theory are characteristically not equations but "existential" assertions. An existential relation is somehow more closely related to choice and decision than to the continuous functional relations of classical analysis. For example, a statement that among the elements of such and such a set there exists one with such and such properties enables us to understand the choice or decision of someone who had previously sought or anticipated such an element. The treatment of strategy and coalition formation in game theory follows just such a scheme. The threads from this treatment to the decision process, to actions based on considerations of power relations, to bargains and agreements are highly suggestive. In its treatment of "power politics," for example, game theory places in the focus of interest not so much the coercive effect of power itself (a quasi-mechanical notion) but rather the potential existence of power combinations, a notion much closer to human affairs. In short, what enters game theory that is completely absent in classical analysis is a consideration of potentialities rather than mechanically acting causes and effects. Such considerations may be as essential to a mathematical theory of human behavior as the dynamic notions of functions and rate of change (absent in ancient mathematics) were for physics. If this is the case, then researches of the type undertaken by Richardson may prove to have only historical value.

Let us now look at the brighter side. It is by no means evident that the gross determinism of the classical physical type assumed by Richardson is not operating in some areas of human behavior. The method of game theory presupposes complete rationality of the participants. Classical physics postulates the operation of blind forces on the "here and now" and denies to matter any imagination, any scanning of alternatives, any choice, or any foresight. Richardson's method is essentially physical. We have listed the possible limitations of this outlook. But the limitations may be by no means absolute. History may be determined to a large extent by waves of mass action, which a mathematician may be able to describe more accurately by the interplay of secular trends, thresholds, equilibriums, etc., than by a sequence of rational decisions. We may also note in passing that what is important in a game of chess (the example we used to point out the limitations of Richardson's method) depends on whether one is a player or a pawn.

Possibly the true nature of large-scale human events is intermediate between physical determinism and cognizant choice based on evaluation of potentialities. If so, then the findings of game theory and systems of differential equations are the two extremes 
bracketing the yet unknown theoretical method suitable for the study of human behavior.

The greatest value of Richardson's work is, however, in my opinion not its scientific value in the narrow sense but in the example set by thirty years of conscientious labor on the frontiers of knowledge. The idea of turning the cold and brilliant light of mathematical investigation on a subject where passions obscure reason is in itself the embodiment of the best in scientific ethics. The idea would not have borne fruit, however, if Richardson had confined himself to exhortations like "Let's be sensible about all this; let's use 'scientific method' to find out what causes wars, armament races, etc." Such exhortations have been common enough and futile enough. Someone had to sit down and try. The results, we have seen, are of uncertain scientific value. The old saw that history never repeats itself rears its ugly head. To test the theory of arms races, Richardson had only three at his disposal, of which only one one behaved "properly." The investigations of the other two were marred by the ambiguity of the data. Significantly, Richardson did not venture to make a definitive prediction about the outcome of the present arms race (started in 1948). And wisely so. From generation to generation new factors appear which make previously reasonable arguments untenable. For example, hydrogen bombs are cheaper than their equivalents in conventional explosives. And weapons of biological warfare are probably cheaper still per unit of "lethality." Therefore, it is conceivable that in the greatest armament race of all, in which conventional weapons would be replaced by nuclear ones, expenditures could actually be shrinking! Again, the concept of intimidation acquires a much different meaning in the nuclear age than what Richardson gives it. Wars of attrition, to which the theory of war moods primarily applies, may also have become obsolete.

But there are other results besides the purely scientific of Richardson's devoted labor. These results are inspirational. Thirty years of painstaking investigation are impressive by anyone's standard. The labor spent seems to put an obligation on future generations of social scientists to continue the search. Some, of course, will scoff at Richardson's shortcomings and at his makeshift theoretical props. But others will take the opportunity to ask, "How can this be done better? What can be salvaged? Where is it worthwhile to follow the paths indicated by Richardson, and where should new ones be struck?" Then these more constructive spirits will go to work. Whether they will succeed in constructing a good mathematical theory of conflict or not, they will be treating conflict with the objectivity of the mathematician, which is the most complete objectivity achievable by man. And this activity may of itseiff have a salutary effect on men's minds. After all, the most important achievement of celestial mechanics was not so much in its utility for calendar-making as in its liberating influence on the human mind. Similarly, "astronomical" methods applied to the investigation of human affairs, if pursued at a rate comparable to the growth of mathematical astronomy at the time of its inception, may yet free us from the compulsions which have been driving us toward destruction.

\section{REF ERENCES}

1. Kermack, W. O., and McKendrick, A. G. "Mathematical Theory of Epidemics," Proc. Roy. Soc. London, A, CXV (1927), 700.

2. Popper, K. R. The Open Society and Its Enemies. Princeton, N.J.: Princeton University Press, 1950. 
3. Rapoport, A. "The Stochastic and the "Teleological' Rationales of Certain Distributions and the So-called Principle of Least Effort," Behavioral Science, II (1957), 147.

4. Richardson, L. F. "Contiguity and Deadly Quarrels: The Local Pacifying Influence," Jour. Roy. Statist. Soc., A, CXV, Part II (1952), 219.

5. Ibid.

6. Ruchardson, L. F. Generalized Foreign Poli- tics. (British Journal of Psychology Monograph Suppl., No. 23.) 1939.

7. - - . "Variation of the Frequency of Fatal Quarrels with Magnitude," Jour. Amer. Statist. Assoc., XLIII ( 1948), 523.

8. - - "War and Eugenics," Eugenics Review, XLII (1950), 25.

9. _-_. "War Moods. I," Psychometrika, XIII, (1948), 147; "War Moods. II," ibid., p. 197. 